University of Warwick institutional repository: http://go.warwick.ac.uk/wrap This paper is made available online in accordance with publisher policies. Please scroll down to view the document itself. Please refer to the repository record for this item and our policy information available from the repository home page for further information.

To see the final version of this paper please visit the publisher's website. Access to the published version may require a subscription.

Author(s): Anders Pedersen, Kefeng Zhang, Kristian Thorup-Kristensen and Lars S. Jensen

Article Title: Modelling diverse root density dynamics and deep nitrogen uptake-A simple approach

Year of publication: 2009

Link to published version:

http://dx.doi.org/10.1007/s11104-009-0028-8

Publisher statement: The original publication is available at www.springerlink.com 
2 Modelling diverse root density dynamics and deep nitrogen uptake - A simple approach

3 Pedersen A. ${ }^{1,2}$, Zhang, K. ${ }^{3}$, Thorup-Kristensen K. ${ }^{2^{*}}$ and Jensen L.S. ${ }^{1}$

4

$5{ }^{1)}$ University of Copenhagen, Faculty of Life Sciences, Department of Agricultural Sciences, Plant

6 and Soil Science, Thorvaldsensvej 40, DK-1871 Frederiksberg C., Denmark.

$7 \quad{ }^{2)}$ University of Aarhus, Faculty of Agricultural Sciences, Department of Horticulture,

8 Kirstinebjergvej 10, DK-5792, Aarslev, Denmark.

9 3) Warwick HRI, the University of Warwick, Wellesbourne, Warwick CV35 9EF, UK

10 *E-mail: ktk@agrsci.dk, Phone: +45 89993228, Fax: +45 89993494

11 Text pages: 29

12 Tables: 1

13 Figures: 12

14 Keywords: EU_rotateN, nitrogen uptake, root depth, root distribution, root model, simulation model 
2 We present a 2-D model for simulation of root density and plant nitrogen (N) uptake for crops

3 grown in agricultural systems, based on a modification of the root density equation originally

4 proposed by Gerwitz and Page (1974). A root system form parameter was introduced to describe the

5 distribution of root length vertically and horizontally in the soil profile. The form parameter can

6 vary from 0 where root density is evenly distributed through the soil profile, to 8 where practically

7 all roots are found near the surface. The root model has other components describing root features,

8 such as specific root length and plant $\mathrm{N}$ uptake kinetics. The same approach is used to distribute

9 root length horizontally, allowing simulation of root growth and plant $\mathrm{N}$ uptake in row crops.

10 The rooting depth penetration rate and depth distribution of root density were found to be the most

11 important parameters controlling crop $\mathrm{N}$ uptake from deeper soil layers. The validity of the root

12 distribution model was tested with field data for white cabbage, red beet, and leek. The model was

13 able to simulate very different root distributions, but it was not able to simulate increasing root

14 density with depth as seen in the experimental results for white cabbage. The model was able to

15 simulate $\mathrm{N}$ depletion in different soil layers in two field studies. One included vegetable crops with

16 very different rooting depths and the other compared effects of spring wheat and winter wheat. In

17 both experiments variation in spring soil $\mathrm{N}$ availability and depth distribution was varied by the use

18 of cover crops. This shows the model sensitivity to the form parameter value and the ability of the

19 model to reproduce $\mathrm{N}$ depletion in soil layers. This work shows that the relatively simple root

20 model developed, driven by degree days and simulated crop growth, can be used to simulate crop

21 soil $\mathrm{N}$ uptake and depletion appropriately in low $\mathrm{N}$ input vegetable production systems, with a

22 requirement of few measured parameters. 
2 Plant and soil models are commonly used to predict crop yield and the environmental impact of

3 crop production. Such models often combine complex modelling of water movement, soil organic

4 matter turnover and aboveground plant growth. Simulation of root growth is an important part,

5 because roots are the link between mineral $\mathrm{N}$ in soil and plant $\mathrm{N}$. Good models of crop root growth

6 is important to simulate $\mathrm{N}$ use efficiency within rotations (Delgado et al. 2000).

7 While the simulation of aboveground plant growth has become increasingly advanced over the

8 years, root modelling has remained fairly simple due to the lack of field data to calibrate more

9 sophisticated root models at field scale. Some root models including detailed modelling of

10 individual roots have been developed (Kohl et al., 2007; Pages et al., 2004). However, such models

11 are mainly used for scientific work and are generally not suitable for simulation of real crop

12 rotations because of a lack of input data and because the models are often only developed for one or

13 a few plant species.

14 Recent field studies have shown that the development of crop rooting depth can be described by a

15 lag phase starting at sowing or transplanting, after which root depth increases linearly with

16 temperature sum (Kage et al., 2000; Smit and Zuin, 1996; Thorup-Kristensen and Van den

17 Boogaard, 1998).

18 Rooting depth and root architecture differ significantly between crop species (Kutschera, 1960). For

19 monocot species, root penetration rates in the range of about $0.2 \mathrm{~mm}$ day-degree ${ }^{-1}$ have been

20 observed for onion (Thorup-Kristensen, 2006a) and 0.8 to $1.2 \mathrm{~mm}$ day-degree ${ }^{-1}$ for cereals and

21 grasses (Thorup-Kristensen, 2001). For dicot species, penetration rates are about 0.7 mm day-

22 degree $^{-1}$ for carrot (Thorup-Kristensen and Van den Boogaard, 1999) and between 1.2 and $2.5 \mathrm{~cm}$ 
1 day-degree ${ }^{-1}$ or even higher for white cabbage and fodder radish (Smit and Groenwold, 2005;

2 Thorup-Kristensen, 2001). Final rooting depth is related to penetration rate and length of growing season. Thus onions develop only a very shallow root system down to approximately 0.2 to $0.3 \mathrm{~m}$

4 (Burns, 1980; Thorup-Kristensen, 2006a), ryegrass roots grow to approximately 1 m while white 5 cabbage, red beet and fodder radish can grow to $2 \mathrm{~m}$ or more (Thorup-Kristensen, 2006b).

6 Monocots and some dicot species have their highest root length densities near the surface, as

7 observed in winter wheat (Asseng et al., 1997; Xue et al., 2003; Zuo et al., 2006), grasses (Smit and 8 Groenwold, 2005; Thorup-Kristensen, 2001) and cauliflower and spinach (Kage et al., 2000; Smit 9 and Groenwold, 2005). However, many dicot species have a more uniform distribution of root 10 length density in the soil profile, often with higher root densities in deeper soil layers than monocot 11 species, as found e.g. for oilseed rape (Barraclough, 1989) and fodder radish (Smit and Groenwold, 12 2005; Thorup-Kristensen, 2006b). For crops grown as row crops, e.g. maize and many vegetable 13 species, a significant difference in root density below and between rows has been shown for maize 14 (Liedgens and Richner, 2001), onion and carrot (Thorup-Kristensen, 2006a; Thorup-Kristensen and 15 van den Boogaard, 1999), whereas lettuce and white cabbage typically show the same root density below and between rows already during their early growth (Thorup-Kristensen, 2006a). The development and proliferation of the roots in soil are affected by intrinsic and extrinsic parameters such as the supply of photosynthates from the shoot, the nutrient status of the plant, soil type and compaction, water potential at the root surface and availability and distribution of nutrients

20 (Bloom et al., 2003; Forde and Lorenzo, 2001). Root penetration rate in root models is often 21 described as being affected by air or soil temperature and a plant-specific growth rate coefficient.

22 The daily growth rate is associated with water stress, soil compaction, clay or sand content and 23 aeration (Penning de Vries et al., 1989). 
1 A number of one-dimensional (1-D) models have been developed for modelling the soil-plant

2 system to enable prediction of plant production, water and nitrogen dynamics in agricultural

3 systems. In 1-D models, the soil column is divided into layers from the surface to a defined depth.

4 Each layer can be assigned standard or specific parameters such as nutrient concentration, water

5 content, temperature, bulk density, or soil strength. As 1-D models only distribute roots according

6 to depth, this prevents them from taking into consideration the uneven root distribution of row

7 crops. Two-dimensional (2-D) and three-dimensional (3-D) root models, on the other hand, are able

8 to simulate spatial differences in nutrient uptake and root distribution of row crops, which leads to

9 much more complex soil water and $\mathrm{N}$ dynamics.

10 Gerwitz and Page (1974) introduced a logarithmic function for root density calculations in 1-D

11 systems. The function gives the percentage of roots for a given rooting depth, with the highest root

12 density near the soil surface. The function has been modified and used in the Daisy model by

13 Abrahamsen and Hansen (2000). Here root density is set to a very low default value at the bottom

14 of the rooting zone, so a very low root density will always be simulated close to the rooting depth;

15 variations in total root length have little effect on subsoil root length and nearly all variation is

16 confined to the surface soil layers. This approach to root modelling prevents the model from

17 simulating the relatively high root densities sometimes observed in deeper soil layers. Further,

18 rooting depth in the model means absolute rooting depth, whereas the measured rooting depths used

19 for parameterization normally does not. In the experimental data roots are also present below the

20 observed rooting depth, and by using these values as estimates of absolute rooting depth in the

21 model, the simulated root exploration of the subsoil will be less efficient than actually indicated by

22 experimental results. 
1 In this work we present a model for root growth and proliferation of root length density in the soil

2 profile, assess whether this model is able to simulate a range of crop root systems, their $\mathrm{N}$ uptake

3 and their soil mineral $\mathrm{N}$ depletion, and compare these against experimental field data. The purpose

4 of this root model is to model a variety of arable and vegetable crop species and reproduce results

5 from field experiments for soil mineral $\mathrm{N}$ depletion with a simple root modelling approach and a

6 minimum of parameters and input requirements.

7 The objective of the present work was to test the ability of the newly developed root model to

8 simulate root development and $\mathrm{N}$ depletion in the soil profile as known from the literature, and to

9 compare simulated soil mineral $\mathrm{N}$ depletion against field observations for vegetable crops with

10 different root patterns. The model was tested with respect to its: a) ability to simulate rooting depth

11 and partitioning of root length density in the rooted zone, b) sensitivity of plant $\mathrm{N}$ uptake to

12 parameter values determining root distribution, root growth and root system $\mathrm{N}$ uptake efficiency,

13 and c) ability to simulate root development and plant $\mathrm{N}$ uptake in row crops. 


\section{Plant and soil modules}

3 The root model operates as a module in an integrated soil-plant-atmosphere model. In brief, other

4 modules in the model include an aboveground crop development and $\mathrm{N}$ demand module

5 (Greenwood et al., 1996; Greenwood et al., 2001), a soil organic matter, soil microbial biomass and

6 decomposition of added organic matter module from the Daisy model (Hansen et al., 1991) and a

7 water balance module (Brisson et al., 2003). While the root model simulate $\mathrm{N}$ uptake processes, the

8 other soil $\mathrm{N}$ processes such as $\mathrm{N}$ mineralization, immobilization, denitrification and ammonia

9 volatilization are modelled as described by Hansen et al. (1991).

10 The model runs on a daily basis. The information fed into the root module from other modules

11 includes soil water content, ammonium and nitrate concentrations, root biomass increment and crop

12 potential water and $\mathrm{N}$ demand, together with the climatic data, soil clay content and bulk density

13 from the model run setup files. All processes are calculated in $0.05 \mathrm{~m}$ x $0.05 \mathrm{~m}$ grid units within the

14 soil domain of $2 \mathrm{~m}$ depth vertically and half the row width horizontally. Root density is calculated

15 in $0.05 \times 0.05 \mathrm{~m}$ soil units, up to $1 \mathrm{~m}$ horizontally (controlled by row width) and to $2 \mathrm{~m}$ depth

16 vertically, and when root depth or width enters the centre of a new soil unit, root density is

17 calculated and plant $\mathrm{N}$ uptake occurs. For crops planted more spatially homogeneously (row width

$18<0.1 \mathrm{~m}$ ), the model operates in 1-D and only one soil column with $0.05 \mathrm{~m}$ width is considered.

\section{Root module - 1-D model}

\section{Root penetration}


1 Root growth calculation is based on cumulative day-degrees (DD, Equation 1), which is common

2 for root models (Kage et al., 2000) and has been shown in field trials to be applicable to both

3 monocot and dicot crops (Kirkegaard and Lilley, 2007; Smit and Groenwold, 2005).

4 Equation $1 D D=\sum T=\left\{\begin{array}{ll}0 & ; T_{\min } \geq T_{\text {air }} \\ T_{\text {air }}-T_{\min } & ; T_{\min } \leq T_{\text {air }}<T_{\max } \\ T_{\max }-T_{\min } & ; T_{\text {air }} \geq T_{\max }\end{array}\right\}$

5 A lag phase $\left(D D_{\text {lag }}\right)$ in terms of $\mathrm{DD}$ is set to account for the period from seed germination or

6 transplanting to root penetration. The root penetration depth $\left(R_{z}\right)$ is calculated as follows.

$7 \quad$ Explanations of abbreviations used in the equations are shown in Table 1.

$8 \quad$ Equation $2 R_{z}=\left\{\begin{array}{ll}\mathrm{R}_{z-\min } & ; \sum D D \leq D D_{\text {lag }} \\ \sum\left(\left(D D-D D_{\text {lag }}\right) k_{r z}\right)+\mathrm{R}_{\mathrm{z}-\min } & ; \sum D D>D D_{\text {lag }} \\ R_{\mathrm{z}-\max } & ; \sum D D-D D_{\text {lag }} k_{r z}+\mathrm{R}_{\mathrm{z}-\min }>R_{\mathrm{z}-\max }\end{array}\right\}$

9 The calculation of root penetration in the horizontal direction is similar with Equation (2), and the

10 calculation is restricted to the rooting depth. The initial root system starts with the root depth $0.1 \mathrm{~m}$

11 and begins to grow horizontally and vertically after the $\mathrm{DD}_{\text {lag. }}$ The model calculates the root

12 penetration depth until $2 \mathrm{~m} . \mathrm{R}_{\mathrm{z}-\mathrm{max}}$ is default $2 \mathrm{~m}$ and can be adjusted in the setup file for soil

13 information.

\section{Root density}

15 The total root length $\left(L_{r}\right)$ is calculated from root biomass $\left(W_{r}\right)$ by assuming a specific root length

16 density $\left(S_{r}\right)$ (Equation 3). The equation for root density distribution is a modified form of the

17 equation suggested by Gerwitz and Page (1974). In the present version, the root density declines by 
1 a logarithmic function down to the simulated rooting depth $R_{z}$, while below $R_{z}$ it decreases linearly

2 to zero at $q=1.3$ (Equation 4$)$.

3 Equation $3 L_{r}=W_{r} S_{r}$

$4 \quad$ Equation $4 L_{z}=\left\{\begin{array}{ll}L_{0} e^{\left(-a_{z} z\right)} & ; \mathrm{z}<R_{z} \\ L_{0} e^{\left(-a_{z} R_{z}\right)}\left(1-\frac{z-R_{z}}{q R_{\mathrm{z}}-R_{\mathrm{z}}}\right) & ; q \mathrm{R}_{\mathrm{z}}>\mathrm{z}>R_{\mathrm{z}} \\ 0 & ; \mathrm{z}>q \mathrm{R}_{\mathrm{z}}\end{array}\right\}$

\section{$5 \quad$ Plant $\mathbf{N}$ uptake}

6 Assuming a uniform distribution of roots in a soil unit, the potential nitrate and ammonium uptake

7 in each unit is calculated by modifying the equation from Nielsen and Barber (1978) with root

8 length as shown in Equation 5.

$9 \quad$ Equation $5 N_{p o t}(i, j)=\frac{L_{r} k N\left(c-c_{\min }\right)}{k f+c}$

10 The calculations for nitrate and ammonium uptake are similar, but they are calculated separately for

11 each unit and accumulated for the whole soil profile. Ammonium only appears in the first 6 soil

12 layers $(0-0.30 \mathrm{~m})$ in the model.

13 Actual plant $\mathrm{N}$ uptake is calculated from the potential $\mathrm{N}$ uptake accumulated for the whole rooted

14 zone and the plant $\mathrm{N}$ demand comes as external information from the crop module. Equation 6

15 shows the calculation of actual plant $\mathrm{N}$ uptake.

16 Equation $6 N_{\text {up }}=N_{\text {demand }}\left(1-\mathrm{e}^{-1 \frac{\mathrm{N}_{\mathrm{pot}}\left(\mathrm{NO}_{3}^{-}\right)+\mathrm{N}_{\mathrm{pot}}\left(\mathrm{NH}_{4}^{+}\right)}{\mathrm{N}_{\mathrm{demand}}}}\right)$ 


\section{2-D root system}

2 In the 2-D model the soil domain is divided into a $0.05 \mathrm{~m} \mathrm{x} 0.05 \mathrm{~m}$ grid. If a row crop has a row

3 width greater than $0.1 \mathrm{~m}$, the root module calculates root density in 2-D. The default root model

4 assumes the same penetration rate in both directions, but different form parameters $\left(a_{z}\right.$ and $\left.a_{x}\right)$ are

5 used for vertical and horizontal root density distribution. Horizontal growth stops in the middle of

6 the inter-row, and competition between crop rows is not allowed in this model.

8 For testing the significance of parameter values, model simulations were run for 110 days starting

9 from 1 April, with typical Danish weather conditions averaged for the period 1960-1990.

\section{Model simulations}

Precipitation/irrigation was set according to evapotranspiration, to ensure a minimum downward percolation of nitrate during the crop growth period. Soil texture was selected so that it did not restrict the root penetration rate and root distribution. The default parameter values in the root module are shown in Table 1 and the method was tested with form parameter value $a_{z}$ ranging from 0 to 8 . Potential crop $\mathrm{N}$ demand in the model corresponded to $250 \mathrm{~kg} \mathrm{~N} \mathrm{ha}^{-1}$ and simulations were carried out for both soil mineral $\mathrm{N}$ contents below and above sufficient supply for this demand. For the low soil $\mathrm{N}$ conditions, 70 and $32 \mathrm{~kg}$ mineral $\mathrm{N} \mathrm{ha}^{-1}$ were distributed in the $0-1$ and $1-2 \mathrm{~m}$ depth, respectively. For the high soil $\mathrm{N}$ conditions, 415 and $185 \mathrm{~kg}$ mineral $\mathrm{N} \mathrm{ha}^{-1}$ were distributed in the 0-1 and 1-2 m depth, respectively. The effects of root penetration rate $k_{r z}$, and plant $\mathrm{N}$ uptake efficiency $k N$ were also studied. To do so, the model was run with settings of $k_{r z}=90 \%$ of default value $\left(0.0009 \mathrm{~m} \mathrm{DD}^{-1}\right)$; and $S_{r}=90 \%$ of the default value $\left(270000 \mathrm{~m} \mathrm{~kg}^{-1} \mathrm{DW}\right)$. In addition, the root depth extension value was tested by setting values of $q=1.3$ (default) and $q=1.0$.

\section{Sensitivity analysis}


1 A sensitivity analysis was carried out for three different parameters in the root model. These were

2 the sensitivity of the root depth penetration rate $\left(k_{r z}\right)$, which controls how fast the roots occupy a

3 new soil layer and soil depth for roots distributed with the logarithmic function; the specific root

4 density $\left(\mathrm{S}_{\mathrm{r}}\right)$, used to calculate the root length in each soil unit influencing the potential and actual

5 plant $\mathrm{N}$ uptake; and the root zone extension depth $(q)$, which is the extra root zone where root

6 density declines linearly below the simulated rooting depth. These three parameters were tested

7 with a range of values for the form parameter in order to test their different influence on plant $\mathrm{N}$

8 uptake.

9 Comparison against experimental data

10 Values of soil mineral $\mathrm{N}$ depletion and root density distribution produced by the model were

11 compared with the results from three field experiments, one including variable $\mathrm{N}$ supply for a white

12 cabbage crop, one comparing $\mathrm{N}$ dynamics in short rotation sequences including vegetable crops

13 with very different root growth (Thorup-Kristensen, 2006b), and one comparing winter wheat and

14 spring wheat with or without a preceding cover crop (Thorup-Kristensen et al., 2009)

In the first experiment white cabbage was transplanted on 18 April and harvested on 21 October 2004. Soil mineral N was measured on 12 May and 26 October 2004. For this study we selected five of the fertiliser levels (A-E) included in this experiment, represented by $Y_{1}: Y_{2}$, where $Y_{1}$ was the $\mathrm{N}$ application in the preceding year (2003) to a cauliflower crop, and $\mathrm{Y}_{2}$ was the $\mathrm{N}$ application on 18 May 2004 (kg mineral $\mathrm{N} \mathrm{ha}^{-1}$ ). The treatments were: A: 0:0, B: 230:0, C: 0:120, D: 230:120 and E: 390:120. No N application in $2003\left(\mathrm{Y}_{1}=0\right)$ resulted in low mineral $\mathrm{N}$ content in spring, whereas the two higher levels of $\mathrm{N}$ application in 2003 left high residual $\mathrm{N}$ levels in the subsoil. Therefore this experiment is ideal for testing the ability to simulate deep root growth and $\mathrm{N}$ acquisition for this root model. The experiment is unpublished but information about soil and 
1 location has been reported elsewhere (Thorup-Kristensen 2006b). Simulated mineral N depletion of

2 soil was tested with different $a_{z}$ values of the white cabbage root model and compared with

3 measured data from this experiment. Crop parameters adopted in simulations were $D D_{\text {lag }} 100, k_{r z}$

4 0.0014. In the simulation, the values $0,1,1.5,2,3,4,5,6,7$, and 8 were tested for parameter $a_{\mathrm{z}}$.

5 Measured plant $\mathrm{N}$ uptake at harvest was compared with the $a_{z}$ parameter. Measured soil mineral $\mathrm{N}$

6 values from the spring were used as initial conditions in the simulations and measured mineral $\mathrm{N}$

7 contents in late October in soil layers 0-1 m and 1-2 m were then compared with the values

8 predicted by the model.

9 The validity of the model was also tested against data from an experiment with three different

10 vegetable crops representing shallow-rooted with low root density (leek), deep-rooted with medium

11 root density (red beet) and deep-rooted with high root density (white cabbage). Leek, red beet and

12 white cabbage were grown after a ryegrass cover crop or no cover crop in the preceding autumn,

13 with two replicates, and the experiment was repeated in two years. Mineral $\mathrm{N}$ in the soil was

14 measured on 18 May and 31 October 2001 and 16 May and 30 October 2002 (Thorup-Kristensen,

15 2006b). Crop parameters adopted in the simulations were: $D D_{\text {lag }} 200, k_{r z} 0.0004, a_{z} 8, a_{x} 8$ for leek,

$16 D D_{\text {lag }} 250, k_{r z} 0.0009, a_{z} 2, a_{x} 2$ for red beet, and $D D_{\text {lag }} 100, k_{r z} 0.001, a_{z} 1.5, a_{x} 1.5$ for white

17 cabbage. Measured soil mineral $\mathrm{N}$ values from the spring were used as initial conditions in the

18 simulations and measured mineral $\mathrm{N}$ contents in late October after vegetable harvest in the soil

19 layers 0-1 and 1-2 m were compared with model simulated results.

20 Finally the model was tested against data from an experiment with comparing winter wheat to

21 spring wheat grown after a cover crop or with no preceding cover crop. The experiment was

22 repeated in three years with different precipitation patterns. The crucifer cover crop was very deep

23 rooted, and the spring and winter wheat crops reached rooting depths of c. 1 and $2 \mathrm{~m}$ depth 
1 respectively (Thorup-Kristensen et al., 2009). Measured soil mineral N values from August before

2 sowing of winter wheat and the cover crop were used as initial conditions in the simulations and

3 measured mineral $\mathrm{N}$ contents in four soil layers (0-0.5, 0.5-1, 1-1.5, and 1.5-2 $\mathrm{m})$ in November and

4 again after wheat harvest in August in the next year were compared to model simulated results.

5 Crop parameters adopted in the simulations were: $D D_{\text {lag }} 100, k_{r z} 0.001, a_{z} 2$ for spring and winter

6 wheat, and $D D_{\text {lag }} 100, k_{r z} 0.0025, a_{z} 1.5$ for the brassica cover crops.

\section{Statistical analysis:}

8 Statistical analyses were conducted to evaluate the performance of the model in predicting soil

9 mineral $\mathrm{N}$ using the Root Mean Square Error (RM+SE) approach. RMSE was calculated as shown

10 in equation 7. Here $O_{i}$ was the observed value in the field experiment and $P_{i}$ was the value predicted

11 by the model, both with units $\left(\mathrm{kg} \mathrm{N} \mathrm{ha}^{-1}\right)$ and with $\mathrm{n}$ number of observations.

12 Equation 7 RMSE $=\sqrt{\sum \frac{\left(O_{i}-P_{i}\right)^{2}}{n}}$ 


\section{Results}

\section{Root density distribution}

3 Figure 1 shows the root length distributions obtained with different values of the parameter $a_{z}$ after

4110 days, equal to $1400 \mathrm{DD}$ and assuming a $q=1.3$ (Table 1 ). With form parameter $a_{z}=0$, the roots

5 were distributed evenly in the soil profile to the current simulated rooting depth, while $a_{z}>0$ gave an

6 exponential decline in root density with depth. When $a_{z}>3$, the majority of the roots were found

7 close to the soil surface. The fraction of root density in the extended zone (controlled by $q$ ) where

8 root density decreases linearly with depth was high when $a_{z}=0$ compared with that calculated with

9 higher $a_{z}$ values.

\section{Plant N uptake}

11 In situations where the mineral $\mathrm{N}$ level in the topsoil was lower than the plant $\mathrm{N}$ demand, the form parameter had a significant impact on plant $\mathrm{N}$ uptake and soil mineral $\mathrm{N}$ depletion. Figure 2 shows model simulations with different form parameter values and their impacts on soil mineral $\mathrm{N}$ depletion, which has the same value as plant $\mathrm{N}$ uptake. The value $a_{z}=0$ resulted in fast plant $\mathrm{N}$ uptake and the highest $\mathrm{N}$ depletion from the soil. The form parameter value $a_{z}=1$ resulted in slightly slower uptake, whereas $a_{z}=3$ or 8 led to more significant reductions in $\mathrm{N}$ uptake.

Soil mineral N depletion occurred rapidly when roots reached the $0.25-0.5 \mathrm{~m}$ soil layer when $a_{z}=0$, 1 or 3 , whereas a form parameter $a_{z}=8$ led to a rather slow depletion of this layer (Figure 3a), when soil $\mathrm{N}$ contents were below plant $\mathrm{N}$ uptake demand. In the $1-1.25 \mathrm{~m}$ soil layer, $a_{\mathrm{z}}=0$ and 1 led to a

20 later but still rather fast mineral $\mathrm{N}$ depletion, but this depletion was slower for $a_{z}=3$ and $a_{z}=8$,

21 where the fractions of plant $\mathrm{N}$ uptake compared to $a_{z}=0$ were only 0.52 and 0.01 respectively at the end of season. In this case, a test showed that when $40 \mathrm{~kg} \mathrm{~N}$ ha $^{-1}$ were added as fertiliser on day 90 
1 in the first soil layer, $99 \%$ of this was taken up within two days with $a_{z}=8$, while it took 12 days

2 with $a_{z}=0$ (data not shown). Simulations where soil mineral $\mathrm{N}$ content exceeded crop $\mathrm{N}$ demand

3 (Figure 3b) showed similar differences, but against a background of generally much less efficient

4 soil mineral $\mathrm{N}$ depletion. While high $a_{z}$ values led to low subsoil root density, they increased topsoil

5 root density and plant $\mathrm{N}$ uptake capacity.

\section{Sensitivity analysis}

7 The sensitivity of $\mathrm{N}$ uptake to variation in root depth penetration rate $\left(K_{r z}\right)$ was moderate, as the

8 reduction in $\mathrm{N}$ uptake was always less than 10\% when depth penetration rate was reduced with $10 \%$

9 (Figure 4a). With form parameter values $a_{z}=1$ and 3, plant $\mathrm{N}$ uptake interacted with root

10 penetration rate, because with these $a_{z}$ values the crop had the potential to produce high root

11 densities and take $\mathrm{N}$ also in deep soil layers, and therefore a delayed depth penetration reduced

12 uptake from deep soil layers. With $a_{z}=8$ plant $\mathrm{N}$ uptake was insensitive to root penetration rate

13 (Figure 4a), as even with the faster root penetration very few roots reached the deep soil layers. For

14 all three $a_{z}$ values the effect on $\mathrm{N}$ uptake relatively stronger during early growth, when the root

15 system was still colonizing $\mathrm{N}$ rich upper soil layers.

16 Simulated $\mathrm{N}$ uptake was found to be sensitive to specific root length parameter $\left(S_{r}\right)$ especially at

17 very early growth stages, whereas during later growth stages the effect almost disappeared. During

18 very early growth $\mathrm{N}$ uptake was reduced by $10 \%$ when $S_{r}$ was reduced to $90 \%$ (Figure $4 \mathrm{~b}$ ). The

19 pattern of response did not vary depending on the $a_{z}$ values.

20 Similarly to root penetration rate, the root zone extension factor $q$ had a larger effect on the relative

21 plant $\mathrm{N}$ uptake during the simulation with low form parameter values than with $a_{z}=8$ where only a

22 small effect were seen and mainly seen during the period from 15 to 60 days after planting (Figure 
$1 \quad 4 c)$. Reducing $K r z$ and removing the $q$ factor both reduce root development at the deeper parts of

2 the root system, and therefore mainly have an effect on root systems which have a significant part

3 of their roots in the deeper part of the root system.

\section{2-D simulation}

6 Figure 5 shows simulated 2-D root density in a soil profile with three different $a_{x}$ values for a crop 7 grown with a row width of $1 \mathrm{~m}$. Simulations with the form parameter values $a_{x}=0$ showed a high

8 and evenly distributed root density in the surface layer. When $a_{x}$ was increased to 3 or 8 , the root

9 density right below the crop row became higher and density in the soil between rows were reduced.

10 Figure 6 shows $\mathrm{N}$ depletion with three different row widths, simulated using $a_{z}=3$ and $a_{x}=3$. When

11 row distance was only $0.1 \mathrm{~m}$, and the model simulates the soil as a 1-D system, the crop depleted 12 the soil mineral $\mathrm{N}$ by $50 \%$ in the $0.25-0.5$ m layer within 40 days and had consumed all available 13 soil mineral $\mathrm{N}$ by day 60 . These values changed to days 50 and 75 for a row width of $0.5 \mathrm{~m}$ and to days 60 and 100 for a row width of $1 \mathrm{~m}$ (Figure 6). With a row distance of $0.5 \mathrm{~m}$ and using the default model setup and parameterization, the simulated $\mathrm{N}$ uptake showed very little sensitivity to variation in the $a_{z}$ value (data not shown).

\section{Model comparison against field experimental data}

19 The value of the form parameter $a_{z}$ for simulating root distribution was tested against data from

20 field experiments. The distribution of roots into depth in the simulations matched root data for

21 cabbage observed with minirhizotrons for days 46 and 64 reasonably well with $a_{z}=1.5$ (Figure 7ab), 
1 but not for day 153 (Figure 7c). Simulated root distribution using $a_{z}$ parameter values between 0

2 and 1.5 had a higher part of the roots below $1 \mathrm{~m}$, and in this way they mimicked the field data from

3 the last measurement date better, whereas when $a_{z}>1.5$ the match became very bad with far too low

4 root densities below $1 \mathrm{~m}$.

5 When the inorganic $\mathrm{N}$ content was lower than plant $\mathrm{N}$ uptake capacity and some soil mineral $\mathrm{N}$ was

6 found in deeper soil layers, simulated crop $\mathrm{N}$ uptake was reduced at high $a_{z}$ parameter values, and

7 predicted plant $\mathrm{N}$ uptake was lower than experimental data, as illustrated with fertiliser levels $\mathrm{A}$ and

8 B in Figure 8a. When high $\mathrm{N}$ levels were found in the 0-1 m soil layer, plant $\mathrm{N}$ uptake in the

9 simulations corresponded to field data and was not sensitive to the $a_{z}$ value, as illustrated with

10 fertiliser levels D and E. Mineral N left by the crop in different soil layers was highly affected by

11 the different $a_{z}$ values (Figure 8bc). For fertiliser levels A, B and C, the model depleted the 0-1 m 12 soil layer to lower $\mathrm{N}$ levels than indicated by field data, and the sensitivity was less than at levels $\mathrm{D}$

13 and $\mathrm{E}$, and at any fertiliser level in the 1-2 m soil layer. The model accurately predicted mineral $\mathrm{N}$

14 content in the 1-2 $\mathrm{m}$ soil layer for $a_{z}=0$ to 2 , indicating that simulation of a high root density below

$151 \mathrm{~m}$ depth is needed to simulate the $\mathrm{N}$ depletion measured in this soil layer in field experiments.

16 Comparing measured soil inorganic $\mathrm{N}$ data to simulations using different $a_{z}$ values for three

17 vegetable crops (Figure 9) show that for cabbage the best fit (lowest RMSE) in both the 0-1 and 1-2

$18 \mathrm{~m}$ soil layers were obtained with $a_{z}=1.5$. Especially in the subsoil the predictions became very bad

19 with higher $a_{z}$ values. With leek the RMSE values for the 0-1 m soil layer declined gradually with

20 increasing $a_{z}$ values, reaching its lowest value at $a_{z}=8$. In the 1-2 m layer there was no effect of

21 changing $a_{z}$, in accordance with the fact that the simulated leek crop did not have any roots below 1

$22 \mathrm{~m}$ (Figure 10). With red beet $a_{z}$ values between 4 and 8 showed low and almost constant RMSE 
1 values in both the 0-1 and 1-2 m soil layers, whereas high RMSE values in the 1-2 m soil layer were

2 found using $a_{z}$ values between 0 and 3.

3 When field observed root distribution of three vegetable crops was compared with simulations, the

4 simulations of the leek root system matched observed data well (Figure 10). Leek had a root

5 distribution with high root density in the topsoil, and then declining fast with depth, corresponding

6 to simulated root density distribution using high $a_{z}$ values. Red beet also showed a reasonable match

7 between measured and simulated data using $a_{z}=2$, though the model overestimated root density in

8 the top $0.25 \mathrm{~m}$, and underestimated root density somewhat between 1 and $1.75 \mathrm{~m}$. Cabbage had a

9 root distribution where the highest root densities were found between 0.75 and 1.5, a distribution

10 which cannot be simulated by the root model, as also illustrated in Figure 7c.

11 The simulated soil mineral $\mathrm{N}$ content after the three vegetable crops following either a ryegrass

12 cover crop or no cover crop in the previous autumn was reasonably correlated with field

13 observations in the $0-1 \mathrm{~m}$ and 1-2 $\mathrm{m}$ soil layers (Figure 11 ). With no cover crop, the $\mathrm{N}$ content in

14 surface soil layer was low and subsoil mineral $\mathrm{N}$ content was high. The model was able to simulate

15 the effects of these different starting conditions, and their interaction with rooting depth of the three 16 vegetable crops. Results revealed that leek only depleted the 0-0.5 m soil layer, due to its shallow 17 root system, while red beet depleted the 0-1 m soil layer and white cabbage the whole 0-2 m layer

18 for mineral $\mathrm{N}$ in the simulations, as well as in the field experiment. In the 0-1 $\mathrm{m}$ soil layer, the 19 model underestimated soil mineral $\mathrm{N}$ content on the day of harvest by on average $33 \%$ or $10 \mathrm{~kg} \mathrm{~N}$ $20 \mathrm{ha}^{-1}$. In the subsoil layer (1-2 m), the model underestimated soil mineral $\mathrm{N}$ content for red beet in

21 the simulations without cover crops, whereas the results for leek and cabbage were in good agreement with the experimental data. Overall, the simulations therefore corresponded well with the 
1 large variation in soil mineral $\mathrm{N}$ content and depth distribution produced by the three very different

2 root systems and the preceding cover crop effect.

3 Finally, the model was tested against a dataset including effects of crops with very different rooting

4 depths and timing of root growth, leading to very different amounts and depth distributions of soil

5 inorganic N. The crops were winter wheat, spring wheat, and a crucifer cover crop followed by

6 spring wheat (Thorup-Kristensen et al., 2009). The simulation covered more than 12 months from

7 sowing of the cover crop in early August to wheat harvest in August of the following year. The

8 results show that the model is able to predict major effects of the experimental treatments and how

9 they interact with weather conditions (Figure 12). In all three years it simulates correctly the fact

10 that the deep rooted crucifer cover crop is able to deplete soil inorganic $\mathrm{N}$ effectively to 2 in

11 November. After wheat harvest in August it simulated repeatedly that spring wheat depleted the top

$120.5 \mathrm{~m}$ as effectively as winter wheat, but that especially from 1 to $2 \mathrm{~m}$ much more inorganic $\mathrm{N}$ was

13 left under spring wheat following bare soil than under winter wheat. In the 1-2 m soil layer it

14 simulated that very little inorganic $\mathrm{N}$ would be present under winter wheat because of its deep

15 rooting and under spring wheat grown after the cover crop, as the cover crop had prevented $\mathrm{N}$

16 leaching to this deep soil layer. The model was even able to simulate that soil inorganic $\mathrm{N}$ content

17 under winter wheat was higher in the 1.5-2 m layer than in the 1-1.5 soil layer, as the winter wheat

18 roots were not fully efficient in the deepest layer. 


\section{Discussion}

\section{Root penetration and density distribution}

3 The assumption of an exponential decrease in root length density with depth has been adopted in

4 several models, with a fixed low root density at the calculated rooting depth, but a varying form

5 factor to distribute increased root length mainly with increasing root density in the uppermost soil

6 layers (Abrahamsen and Hansen, 2000; Barraclough and Leigh, 1984; Greenwood et al., 1982).

7 This exponential decrease has been shown to match monocots such as grasses and cereals

8 reasonably well and was demonstrated here also for the vegetable crop leek, but not for dicot

9 species such as oil radish or winter rape (Thorup-Kristensen, 2001). In the model presented here, it

10 was possible to vary the root length density distribution among soil layers, and to increase root

11 length density in deeper soil layers using a fixed value of the form parameter but allowing root

12 density to vary at calculated rooting depth. This variation in root distribution provides the

13 opportunity to simulate a range of different crop species with significantly different root

14 distribution. The model still had problems simulating the deep root distribution of dicot species

15 such as white cabbage in late season (Figure 7), but agreement was satisfactory in the earlier part of

16 the growing season. Using an exponential equation for root density distribution only fully agrees

17 with most monocot species and some dicot species. However, the purpose of developing this model

18 was not to simulate root depth distribution very closely, but mainly to develop a root model where it

19 was possible to simulate crop $\mathrm{N}$ uptake from deeper soil layers more appropriately compared with

20 existing crop models used today.

\section{Plant $\mathbf{N}$ uptake}


1 The root model showed plant $\mathrm{N}$ uptake from the entire rooted zone, even when there was a high $\mathrm{N}$

2 level in the topsoil. Field experiments with high mineral $\mathrm{N}$ level in the topsoil layer also show some

3 plant $\mathrm{N}$ uptake from deeper soil layers, indicating that this approach complies with field

4 observations (Thorup-Kristensen and van den Boogaard, 1998). Plant N uptake from all of the

5 rooted zone was also supported by a field study where ${ }^{15} \mathrm{~N}$ was added at 0.6 to $1.4 \mathrm{~m}$ depth in a

6 carrot crop and from 1 to 2.5m in a cabbage crop (Kristensen and Thorup-Kristensen, 2004). For

7 both crops a high $\mathrm{N}$ inflow rate was found from all positions within the estimated depth of the crop

8 rooting zone, showing that the crops can deplete deep soil layers for mineral N. In a field

9 experiment where sugar beet was grown, nitrate concentration was measured in three soil layers (0-

$10 \quad 0.2,0.2-0.4$ and $0.4-0.7 \mathrm{~m}$ depth) and these data showed a two-week delay in $\mathrm{N}$ depletion in the $0.4-$

$110.7 \mathrm{~m}$ layer compared with the two layers above (Schmied et al., 2000). Furthermore, the two layers

12 nearer the surface were depleted to the same soil mineral $\mathrm{N}$ concentration at harvest, whereas the

13 deepest layer had a higher soil mineral $\mathrm{N}$ concentration. Such a delay in $\mathrm{N}$ depletion simulated by

14 the model is also shown in Figure 3, where depletion of the 1-1.25 m soil layer began at day 75 . The

15 efficiency of plant $\mathrm{N}$ uptake in this layer was dependent on the root density distribution, determined

16 by $a_{z}$ and plant $\mathrm{N}$ demand and mineral $\mathrm{N}$ level in soil layers above.

17 Simulated depletion of mineral $\mathrm{N}$ down the soil profile was highly sensitive to the value of the form

18 parameter. This makes the description of the root distribution flexible and makes it possible to

19 represent root systems from crops with very different root profiles. Sensitivity of plant N uptake to

20 other parameters was also analysed. The root penetration rate was particularly important for

21 simulation of crops with low $a_{z}$ value, whereas in the simulations using a high $a_{z}$ value the subsoil

22 root density was low, and thus, absolute rooting depth became less important. For the same reason,

23 simulation results are only sensitive to the $q$-parameter, when $a_{z}$ is low. The sensitivity to the $q$ -

24 parameter may be too low at high $a_{z}$ values, as Kristensen and Thorup-Kristensen (2004) found 
1 significant plant $15 \mathrm{~N}$ uptake from soil layers below the estimated rooting depth of carrot and sweet corn, crops which had a clear decline in root density with depth, i.e. a high $a_{z}$ value.

3 During early crop growth the simulation of plant $\mathrm{N}$ uptake was sensitive to the specific root length

$4\left(S_{r}\right)$, affecting total crop root length, but the importance of this parameter decreased during the

5 simulation. In the beginning of the simulation a 10\% reduction in the specific rooting length

6 resulted in a $10 \%$ reduction in plant $\mathrm{N}$ uptake, but after about 50 days the effect had almost

7 disappeared. Such a result is in accordance with the general observation that root growth can often

8 limit crop nutrient uptake during early growth (e.g. Costigan (1988)), but later during growth the

9 root system capacity for nutrient uptake is often much higher than the crop demand. Further, this

10 pattern makes sense, as during early root colonisation of a soil volume, the roots will not yet have

11 affected soil mineral $\mathrm{N}$ concentration, and the root length will be the main varying factor. Later, this

12 will be compensated as high root density leads to fast soil mineral $\mathrm{N}$ depletion and therefore

13 reduced uptake at a later stage, while soil volumes with fewer roots will sustain some plant $\mathrm{N}$

14 uptake for a longer time.

15 When fertilizer was added at the surface and in surplus of the plant $\mathrm{N}$ demand the simulations show that plant $\mathrm{N}$ uptake become independent of the $a_{z}$ value, showing that the value of $a_{z}$ is mainly important for crop $\mathrm{N}$ uptake when too little $\mathrm{N}$ is available in the topsoil. At high $\mathrm{N}$ supply the value

18 of $a_{z}$ only affects the depth distribution of $\mathrm{N}$ left in the soil. Further the test showed that the

19 simulations with high $a_{z}$ deplete the soil layer 0-1 m more effectively than is measured in the field.

20 This opportunity to alter root distribution is important to allow plant models to describe mineral $\mathrm{N}$

21 dynamics in mixed rotations of arable and vegetable crops in low or reduced input agricultural

22 systems, because root distributions differ strongly among arable and vegetable crops (Smit and

23 Groenwold, 2005; Thorup-Kristensen, 2006b) and with a demand for reduced $\mathrm{N}$ fertilization to 
1 protect the environment, less fertilizer $\mathrm{N}$ will be added and there will be more focus on cover crop use and utilization of residual mineral $\mathrm{N}$ in deeper soil layers.

3 Comparisons between measured and simulated vegetable crops of leek, red beet and white cabbage

4 (Figures 8 and 11) showed that the model could be parameterized to simulate the measured

5 depletion of $\mathrm{N}$ from the $0-1 \mathrm{~m}$ and 1-2 $\mathrm{m}$ layers in the autumn at vegetable harvest. This was found on a background of very different $\mathrm{N}$ content in the 1-2 $\mathrm{m}$ soil layer in the spring before planting of vegetables. This was possible even though the simulated root distribution does not comply

8 accurately with the root distribution measured in the field (Figure 10), but it has previously been

9 shown that rooting depth may be more important than root density distribution for determining the 10 ability of crops to deplete soil inorganic N (Thorup-Kristensen, 2001). Robinson et al. (1994)

11 showed another example based on a ${ }^{15} \mathrm{~N}$ study, where soil mineral $\mathrm{N}$ was depleted most efficiently by the crop with the lowest root length density, in this case because of interactions with above 13 ground plant $\mathrm{N}$ status.

14 The strongest deviation between measured and simulated data was found for red beet in the 1-2 $\mathrm{m}$ 15 soil layer (Figure 11), where the model simulated lower $\mathrm{N}$ content than found in the experiment. This is also the reason why the model optimization showed that an $a_{z}$ value above 4 would give the best simulation of red beet soil $\mathrm{N}$ depletion (Figure 9), while it would clearly not simulate a root system matching the one measured on red beet. This deviation may be due to the simplicity of the crop model used. In this model crop growth, root growth and $\mathrm{N}$ uptake continues at full rate until 20 the date of harvest. This is relevant for many of the vegetable crops the EU_Rotate model was 21 developed to simulate, but not for all. Root and tuber crops as onion, potato, red beet, and carrot will cease to produce leaves during late growth stages while tubers are still growing. Thus, the observation that red beet did not effectively deplete the deeper parts of its root zone may be due to a 
1 low $\mathrm{N}$ demand at the late part of its growth period, when the deeper parts of the root system were

2 developed. In the model simulation this result can be mimicked by using an unrealistically high

3 value of $a_{z}$, to create a very low subsoil root density. However, developing a crop growth model

4 allowing reduced $\mathrm{N}$ demand at late growth stages would be more relevant, also for simulation of

5 cereal crops which mature and die off at the end of their growth.

6 Row crops such as carrots and maize have different rooting depth and root density beneath the crop

7 rows and in the interrow soil. This root distribution leads to a lower or delayed $\mathrm{N}$ depletion in the

8 soil between rows, as has been demonstrated in field experiments (Liedgens and Richner, 2001;

9 Schröder et al., 1996; Thorup-Kristensen, 2006a). The model showed high sensitivity to row

10 distance, but did not show high difference in $\mathrm{N}$ depletion with variation of the $a_{x}$ form parameter.

11 The model simulations are likely to be more sensitive to variation in $a_{x}$ when simulating crops with

12 slow root growth, than with the faster root growth in the tests made here, but there is a lack of

13 experimental data available to qualify such tests. The 2-D model will be useful for simulating the

14 delay in soil mineral $\mathrm{N}$ availability to row crops compared to other crops, which will be especially

15 important for vegetable crops which are harvested at early growth stages.

16 All in all we find that the root model presented in this paper is an improvement compared to other

17 simple root models used for crop-soil N simulation models. It can simulate the variable ability of

18 crop species to build high root density and $\mathrm{N}$ uptake capacity in deep soil layers, and do so in a very

19 simple way. The tests of the ability of the root model as part of the full EU-Rotate model to

20 simulate effects of cover crops and main crops with highly variable root growth and timing of root

21 growth shown in Figure 11 and 12 demonstrate that it allow the model to simulate main effects of roots on $\mathrm{N}$ use efficiency which is important e.g. for model simulations of environmental effects. 


\section{1}

Conclusions

2 The root modelling approach used in the present study involved simulating the development of

3 rooting depth, root density distribution with depth, and plant $\mathrm{N}$ uptake. The model can be

4 parameterised to simulate observed differences in root growth among species of vegetable and

5 arable crops using only a few parameters, such as root system form, lag phase for germination and

14 depths.

\section{Acknowledgements} http://www2.warwick.ac.uk/fac/sci/whri/research/nitrogenandenvironment/eurotaten/

21 The authors gratefully acknowledge additional funding for this work from the European root penetration rate. This model could simulate experimental data for root distribution of monocot crops, whereas for deep-rooted dicot crops, the simulated root density in the lower part of the rooting zone were too low compared with experimental data. However, by varying the $a_{z}$ value, the model was capable to predict $\mathrm{N}$ depletion in surface and subsoil layers reasonably well after crops with different $\mathrm{N}$ demand, rooting depth and depth distribution of the root system, which is important for simulating nitrogen use efficiency as well as nitrogen losses from agricultural and horticultural rotations. The 2-D root model approach used made the model able to simulate soil mineral $\mathrm{N}$ depletion both horizontal and vertically to comply with different row width and rooting Root sub-module was developed in the European Community Network project: Development of a model-based decision support system to optimise nitrogen use in horticultural crop rotations across Europe (EU-Rotate_N) under Framework 5. For more information about the plant soil model and access to downloads see: Community under the Sixth Framework Programme, for the Integrated Project 
1 QUALITYLOWINPUTFOOD, FP6-FOOD-CT-2003-9 506358 and from the UK Department for

2 Environment, Food and Rural Affairs who through project HH3509SFV. 
References

Abrahamsen P and Hansen S 2000 Daisy: an open soil-crop-atmosphere system model. Environ.

Model. Soft. 15, 313-330.

Asseng S, Richter C and Wessolek G 1997 Modelling root growth of wheat as the linkage between crop and soil. Plant Soil 190, 267-277.

Barraclough P B 1989 Root growth, macro-nutrient uptake dynamics and soil fertility requirements of a high yielding winter oilseed rape crop. Plant Soil 119, 59-70.

Barraclough P B and Leigh R A 1984 The growth and activity of winter wheat roots in the field: The effect of sowing date and soil type on root growth of high-yielding crops. J. Agr. Sci. 103, 5974.

Bloom A, Meyerhoff P, Taylor A and Rost T 2003 Root Development and Absorption of Ammonium and Nitrate from the Rhizosphere. Journal of Plant Growth Regulation 21, 416-431.

Brisson N, Gary C, Justes E, Roche R, Mary B, Ripoche D, Zimmer D, Sierra J, Bertuzzi P, Burger P, Bussiere F, Cabidoche Y M, Cellier P, Debaeke P, Gaudillere J P, Henault C, Maraux F, Seguin B and Sinoquet H 2003 An overview of the crop model stics. Eur. J. Agron. 18, 309-332.

Burns I G 1980 Influence of the spatial distribution of nitrate on the uptake of N by plants: A review and a model for rooting depth. J. Soil Sci. 31, 155-173.

Costigan P A 1988 The placement of starter fertilizers to improve the early growth of drilled and transplanted vegetables. Proceedings of the Fertilizer Society 274.

Delgado J A, Follett R F, Shaffer M J 2000 Simulation of nitrate-nitrogen dynamics for cropping systems with different rooting depths. Soil Sci Soc Am J 64, 1050-1054

Forde B G and Lorenzo H 2001 The nutritional control of root development. Plant Soil 232, 51-68.

Gerwitz A and Page E R 1974 Empirical Mathematical-Model to Describe Plant Root Systems. J. Appl. Ecol. 11, 773-781.

Greenwood D J, Gerwitz A, Stone D A and Barnes A 1982 Root development of vegetable crops. Plant Soil 68, 75-96.

Greenwood D J, Rahn C, Draycott A, Vaidyanathan L V and Paterson C 1996 Modelling and measurement of the effects of fertilizer- $\mathrm{N}$ and crop residue incorporation on $\mathrm{N}$-dynamics in vegetable cropping. Soil Use \& Management 12, 13-24.

Greenwood D J, Rahn C, Draycott A, Vaidyanathan L V and Paterson C 2001 Modelling Nresponse of field vegetable crops grown under diverse conditions with N_ABLE: A review. Journal of Plant Nutrition 24, 1799-1815. biomass production in winter wheat using the Danish simulation model daisy. Fertil. Res. 27, 24535 259. 
Kage H, Kochler K and Stützel H 2000 Root growth of cauliflower (Brassica oleracea L. botrytis) under unstressed conditions: Measurement and modelling. Plant Soil 223, 133-147.

3 Kirkegaard J A and Lilley J M 2007 Root penetration rate - a benchmark to identify soil and plant limitations to rooting depth in wheat. Aust. J. Exp. Agr. 47, 590-602.

5 Kohl M, Büttcher U and Kage H 2007 Comparing different approaches to calculate the effects of heterogeneous root distribution on nutrient uptake: a case study on subsoil nitrate uptake by a barley root system. Plant Soil 298, 145-159.

Kristensen H L and Thorup-Kristensen K 2004 Uptake of (15)N labeled nitrate by root systems of sweet corn, carrot and white cabbage from 0.2 to 2.5 meters depth. Plant Soil 265, 93-100.

Kutschera L 1960 Wurzelatlas mitteleuräischer Ackerunkrüter und Kulturpflanzen. DLG Verlag,

11 Frankfurt-am-Main.

Liedgens M and Richner W 2001 Minirhizotron observations of the spatial distribution of the maize root system. Agron. J. 93, 1097-1104.

Nielsen N E and Barber S A 1978 Diffferences Among Genotypes of Corn in the Kinitics of P Uptake. Agron. J. 70, 695-698.

Pages L, Vercambre G, Drouet J-L, Leccompte F, Collet C and Le Bot J 2004 Root Typ: a generic model to depict and analyse the root system architecture. Plant Soil 258, 103-119.

Penning de Vries F W T, Jansen D M, ten Berge H F M and Bakeman A 1989 Simulation of ecophsiological processes of growth in several annual crops. Pudoc: Wageningen,The Netherlands.

Robinson D, Linehan D J and Gordon D C 1994 Capture of nitrate from soil by wheat in relation to root length, nitrogen inflow and availability. New Phytol. 128, 297-305.

Schmied B, Abbaspour K and Schulin R 2000 Inverse Estimation of Parameters in a Nitrogen Model Using Field Data. Soil Sci. Soc. Am. J. 64, 533-542.

Schröder J J, Groenwold J and Zaharieva T 1996 Soil mineral nitrogen availability to young maize plants as related to root length density distribution and fertilizer application method. Neth. J. Agr. Sci. 44, 209-225.

Smit A L and Groenwold J 2005 Root characteristics of selected field crops: Data from the Wageningen Rhizolab (1990-2002). Plant Soil 272, 365-384.

Smit A L and Zuin A 1996 Root growth dynamics of Brussels sprouts (Brassica olearacea var. gemmifera) and leeks (Allium porrum L.) as reflected by root length, root colour and UV fluorescence. Plant Soil 185, 271-280.

Thorup-Kristensen K 2006a Root growth and nitrogen uptake of carrot, early cabbage, onion and lettuce following a range of green manures. Soil Use Manag. 22, 29-39. 
1 Thorup-Kristensen K 2001 Are differences in root growth of nitrogen catch crops important for 2 their ability to reduce soil nitrate-N content, and how can this be measured? Plant Soil 230, 1853195.

4 Thorup-Kristensen K 2006b Effect of deep and shallow root systems on the dynamics of soil 5 inorganic N during 3-year crop rotations. Plant Soil 288, 233-248.

6 Thorup-Kristensen, K., Salmeron, M. and Loges, R. (2009) Winter wheat roots grow twice as deep 7 as spring wheat roots, is this important for $\mathrm{N}$ uptake and $\mathrm{N}$ leaching loss? Plant and Soil (DOI:

8 10.1007/s11104-009-9898-z)

9 Thorup-Kristensen K and van den Boogaard R 1998 Temporal and spatial root development of 10 cauliflower (Brassica oleracea L. var. botrytis L.). Plant Soil 201, 37-47.

11 Thorup-Kristensen K and van den Boogaard R 1999 Vertical and horizontal development of the 12 root system of carrots following green manure. Plant Soil 212, 143-151.

13 Xue Q, Zhu Z, Musick J T, Stewart B A and Dusek D A 2003 Root growth and water uptake in 14 winter wheat under deficit irrigation. Plant Soil 257, 151-161.

15 Zuo Q, Shi J, Li Y and Zhang R 2006 Root length density and water uptake distributions of winter 16 wheat under sub-irrigatio. Plant Soil 285, 45-55. 
2 Table 1. List of abbreviations, initial value if needed, units and explanation

\begin{tabular}{|c|c|c|c|}
\hline Name & Default value & Unit & Explanation \\
\hline \multicolumn{4}{|c|}{ Model parameters } \\
\hline$a_{z}$ & {$[0,1 . .8]$} & - & Form parameter, vertically \\
\hline$a_{x}$ & {$[0,1 . .8]$} & - & Form parameter, horizontally \\
\hline$c$ & - & [kg N m-3] & Nitrate or ammonium content in soil unit \\
\hline cmin & $0.001 / 0.002$ & {$[\mathrm{~kg} \mathrm{~N} \mathrm{m-3]}$} & $\begin{array}{l}\text { Minimum nitrate / ammonium concentration allowing } \mathrm{N} \\
\text { uptake from a soil unit }\end{array}$ \\
\hline$k f$ & 1.45 & - & Parameter reducing root $\mathrm{N}$ uptake at low $\mathrm{N}$ concentrations \\
\hline$k N$ & 0.07 & - & Root $\mathrm{N}$ uptake efficiency parameter \\
\hline$k_{r z}$ & - & {$\left[\mathrm{m}\right.$ day $\left.{ }^{-1}{ }^{\circ} \mathrm{C}^{-1}\right]$} & Vertical root penetration rate parameter \\
\hline$k_{r x}$ & - & {$\left[\mathrm{m}\right.$ day $\left.^{-1}{ }^{\circ} \mathrm{C}^{-1}\right]$} & Horizontal root penetration rate parameter \\
\hline$q$ & 1.3 & - & Absolute rooting depth relative to simulated rooting depth \\
\hline$R_{x}$ & - & {$[\mathrm{m}]$} & Root system width \\
\hline$\hat{R_{\mathrm{z}}}$ & - & [m] & Vertical root depth \\
\hline$R_{\text {z-max }}$ & - & [m] & Maximum rooting depth \\
\hline$R_{z-\min }$ & 0.10 & {$[\mathrm{~m}]$} & Rooting depth at sowing or planting \\
\hline$S_{r}$ & 300000 & {$\left[\mathrm{mg}^{-1}\right]$} & Specific root density \\
\hline$T_{\min }$ & 0 & {$\left[{ }^{\circ} \mathrm{C}\right]$} & Minimum temperature for root growth (crop dependant) \\
\hline$T_{\max }$ & $\mathrm{T}_{\min }+20$ & {$\left[{ }^{\circ} \mathrm{C}\right]$} & Maximum temperature for root growth \\
\hline$D D$ & - & - & Day-degrees \\
\hline$D D_{\text {lag }}$ & - & [DD] & Lag phase for initiating root growth \\
\hline$T$ & - & {$\left[{ }^{\circ} \mathrm{C}\right]$} & Temperature \\
\hline$T_{l a g}$ & - & [DD] & Lag phase for initiating root growth \\
\hline$L_{0}$ & - & {$\left[\mathrm{m} \mathrm{m}^{-3}\right]$} & Root density at surface \\
\hline$L_{r}$ & - & {$\left[\mathrm{m} \mathrm{m}^{-2}\right]$} & Total root length \\
\hline$L_{z}$ & - & {$\left[\mathrm{m} \mathrm{m}^{-3}\right]$} & Root density at soil depth z \\
\hline$N_{\text {demand }}$ & - & {$\left[\mathrm{kg} \mathrm{N} \mathrm{ha}^{-1} \mathrm{~d}^{-1}\right]$} & Nitrogen demand calculated \\
\hline$N_{\text {pot }}(i, j)$ & - & {$[\mathrm{kg} \mathrm{N}]$} & $\begin{array}{l}\text { Potential nitrate or ammonium } \mathrm{N} \text { uptake for each soil unit } \\
(\mathrm{i}, \mathrm{j}) \text {, where i denotes depth and j denotes width }\end{array}$ \\
\hline$N_{\text {pot }}$ & - & {$\left[\mathrm{kg} \mathrm{N} \mathrm{ha}^{-1}\right]$} & Potential daily N uptake from the whole root zone \\
\hline$N_{u p}$ & - & {$\left[\mathrm{kg} \mathrm{N} \mathrm{ha}^{-1}\right]$} & Actual nitrate and ammonium plant uptake \\
\hline$W_{r}$ & - & {$\left[\mathrm{g} \mathrm{m}^{-2}\right]$} & Root biomass \\
\hline Z & - & [m] & Soil depth \\
\hline
\end{tabular}


1 Table 2. Relative plant $\mathrm{N}$ uptake in the 1.0-1.25 m soil layer. Simulation with the default model settings and simulation

2 for testing model sensitivity for root penetration rate, specific root length and root extension.

\begin{tabular}{|c|c|c|c|c|}
\hline \multirow[b]{2}{*}{$\begin{array}{l}\text { Form } \\
\text { parameter } a_{z}\end{array}$} & \multirow{2}{*}{$\begin{array}{l}\text { Default parameters } \\
\text { Plant } N \text { uptake, relative } \\
\text { to } a_{z}=0\end{array}$} & \multicolumn{3}{|c|}{$\begin{array}{l}\text { Model parameter sensitivity } \\
\text { Plant N uptake, relative to default } k_{r z}, s_{r} \text { or } q \text { with } a_{z}=0 \text { to } 8^{* *}\end{array}$} \\
\hline & & $\boldsymbol{k}_{r z 90 \%}$ & $S_{r 90 \%}$ & $q=1$ \\
\hline 0 & 1.0 & 0.98 & 1.00 & 0.94 \\
\hline 0.5 & 0.99 & 0.96 & 0.99 & 0.91 \\
\hline 1 & 0.96 & 0.93 & 0.98 & 0.87 \\
\hline 2 & 0.80 & 0.86 & 0.96 & 0.78 \\
\hline 3 & 0.52 & 0.81 & 0.93 & 0.71 \\
\hline 5 & 0.12 & 0.77 & 0.90 & 0.67 \\
\hline 8 & 0.01 & 0.76 & 0.89 & 0.68 \\
\hline
\end{tabular}

$3 \quad{ }^{*}$ : derived as plant $\mathrm{N}$ uptake with $a_{\mathrm{z}}=0, . .8$ / plant $\mathrm{N}$ uptake with $a_{\mathrm{z}}=0$

$4 \quad{ }^{* *}$ : derived as plant $\mathrm{N}$ uptake with $k_{r z 90 \%}$ / plant N uptake at $k r_{z}$, for each $a_{z}=0 \ldots 8$ (column 2) and similar for $S_{r 90 \%}$ and $5 q=1$.

6 


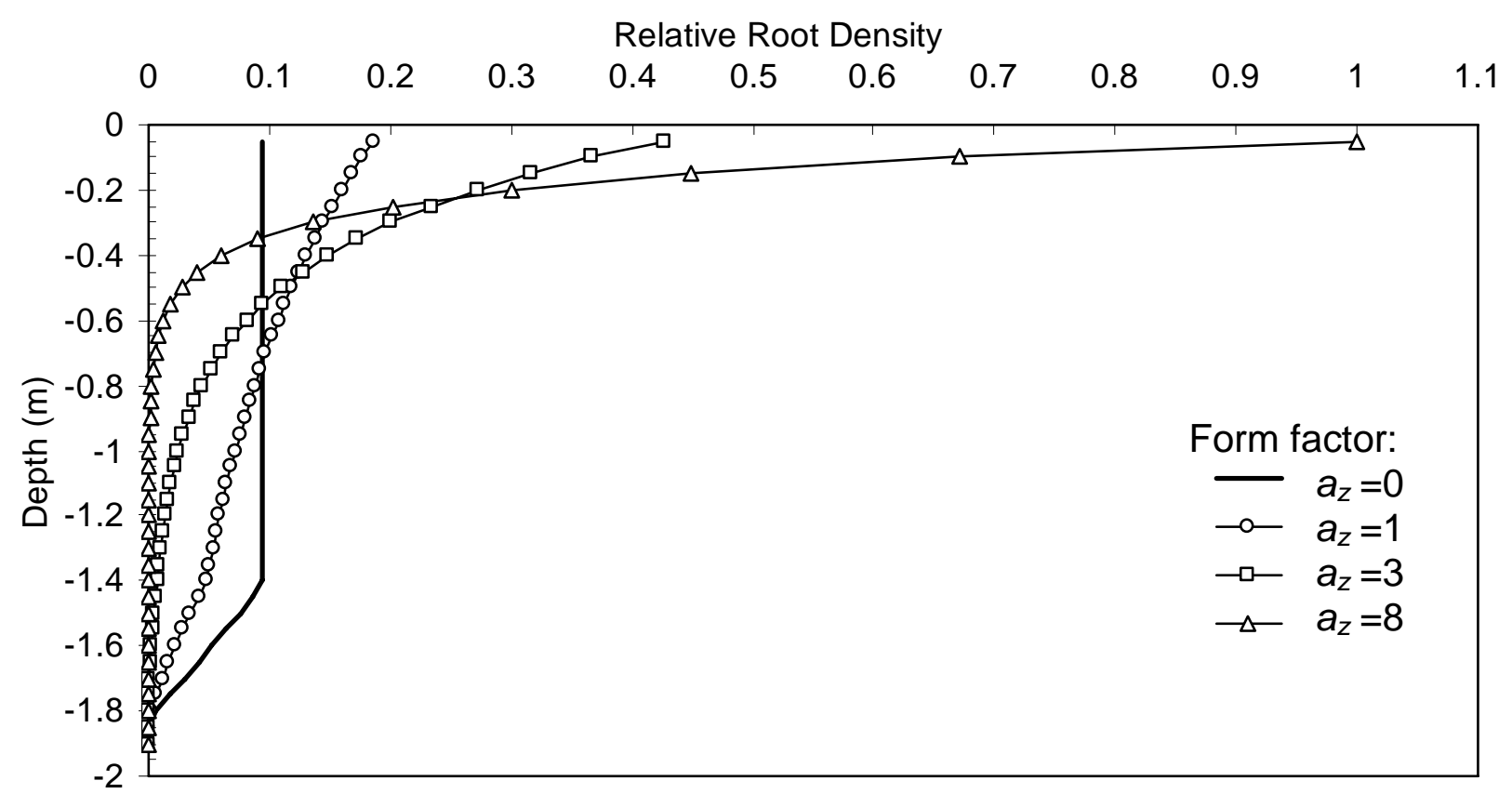

3 Figure 1. Relative modelled root density distribution in soil profile after 110 days with different values of $a_{z}$. Total root

4 biomass and root length were identical in all simulations. Default setting of root parameters include $q=1.3$ 


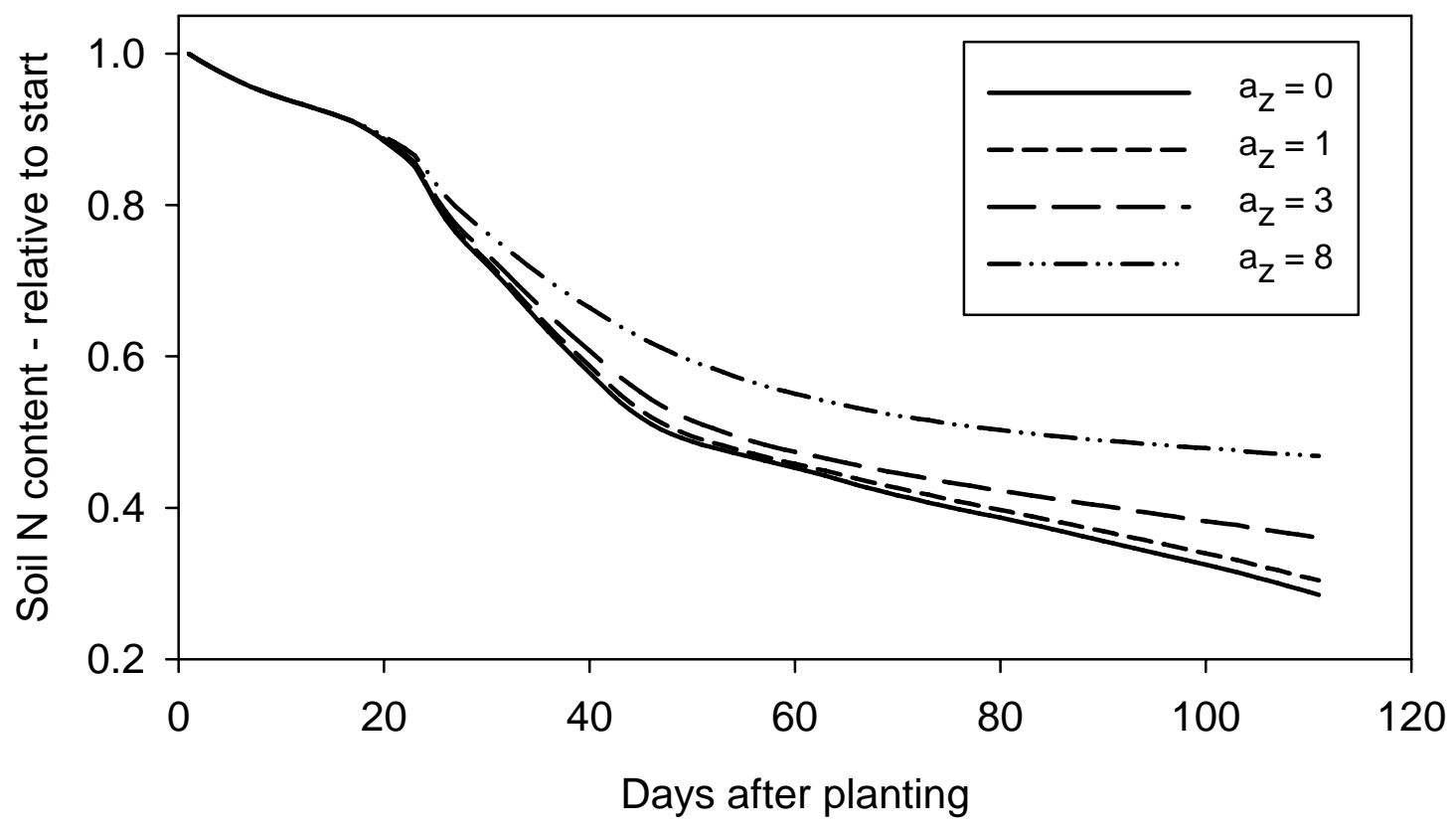

2 Figure 2. Relative soil mineral $\mathrm{N}$ content in the 0-2.0 m soil layer compared with initial soil mineral $\mathrm{N}$ content for form

3 parameter az=0, 1, 3 and 8 for default root model simulation in a situation where soil mineral $\mathrm{N}$ level was below

4 potential plant $\mathrm{N}$ uptake. 


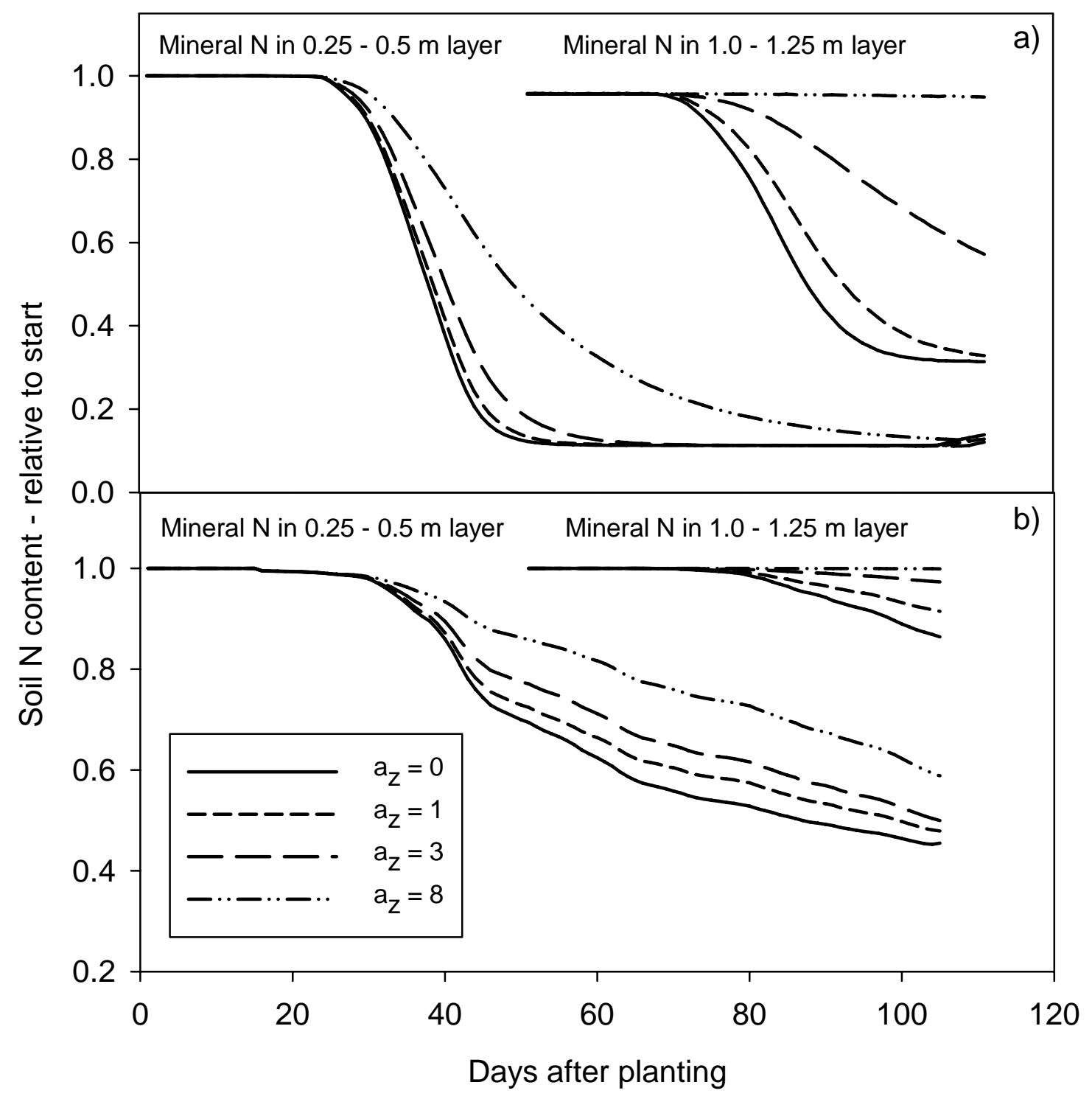

2 Figure 3. Soil mineral $\mathrm{N}$ content in two soil layers, relative to initial start content for default root model for form

3 parameter $a_{z}=0,1,3$ and 8 in $0.25-0.50 \mathrm{~m}$ and 1.00-1.25 m soil layers. a) Low $\mathrm{N}$ conditions, below potential uptake for

4 the root model. b) High $\mathrm{N}$ conditions, corresponding to potential plant $\mathrm{N}$ uptake for the root model. 


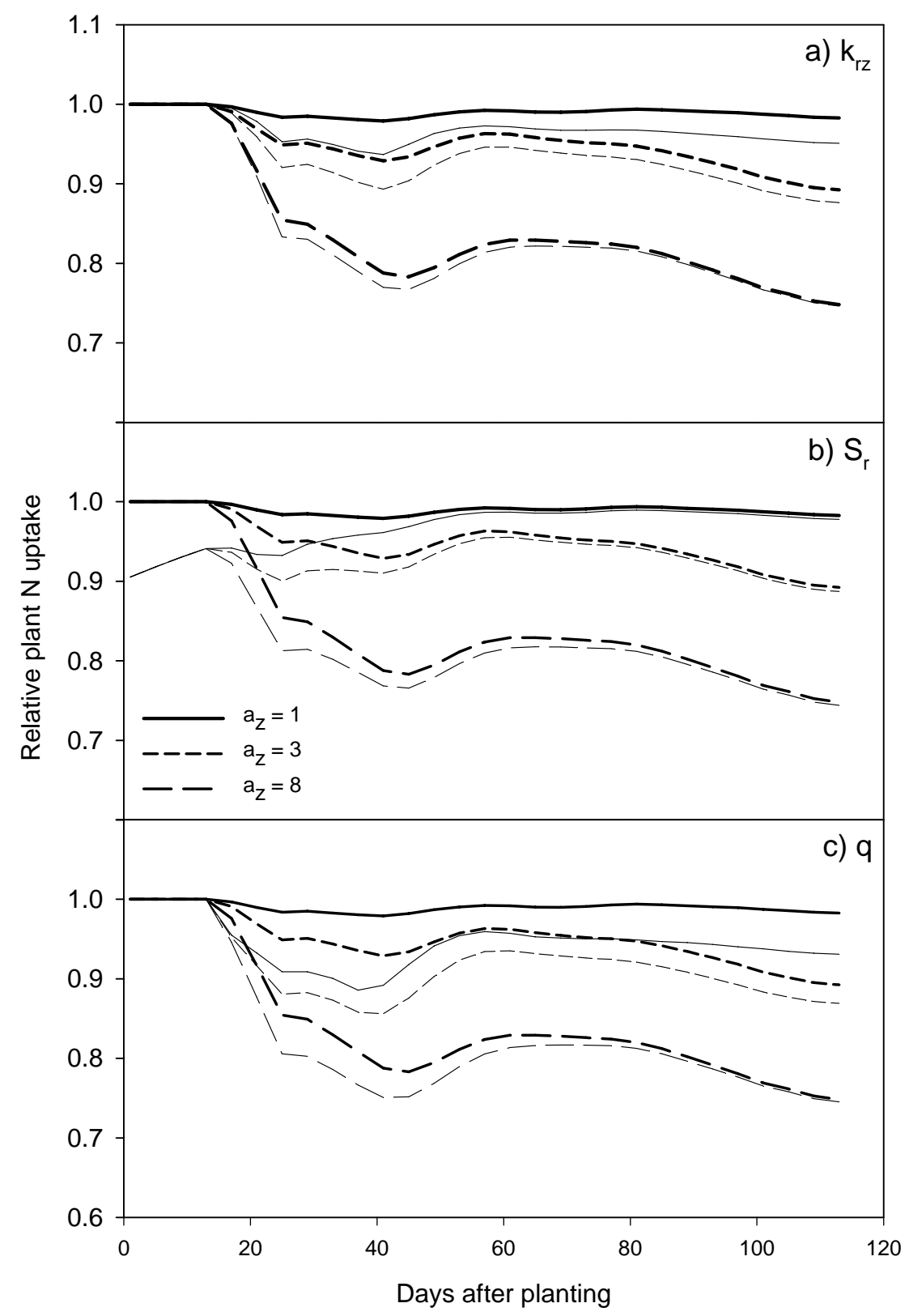

2 Figure 4. Sensitivity of plant $\mathrm{N}$ uptake to three main parameters. Heavy lines show uptake using form parameter $a_{z}=1$,

33 and 8 relative to uptake with $a_{z}=0$. Thin lines show same simulations but with altered parameter values: a) root

4 penetration rate $\left(k_{r z}\right)$ reduced to $90 \%$ of default setting, b) specific root length $\left(S_{r}\right)$ reduced to $90 \%$ of default setting, and

5 c) without linear root part ( $q=1)$ compared to the default ( $q=1.3)$. 


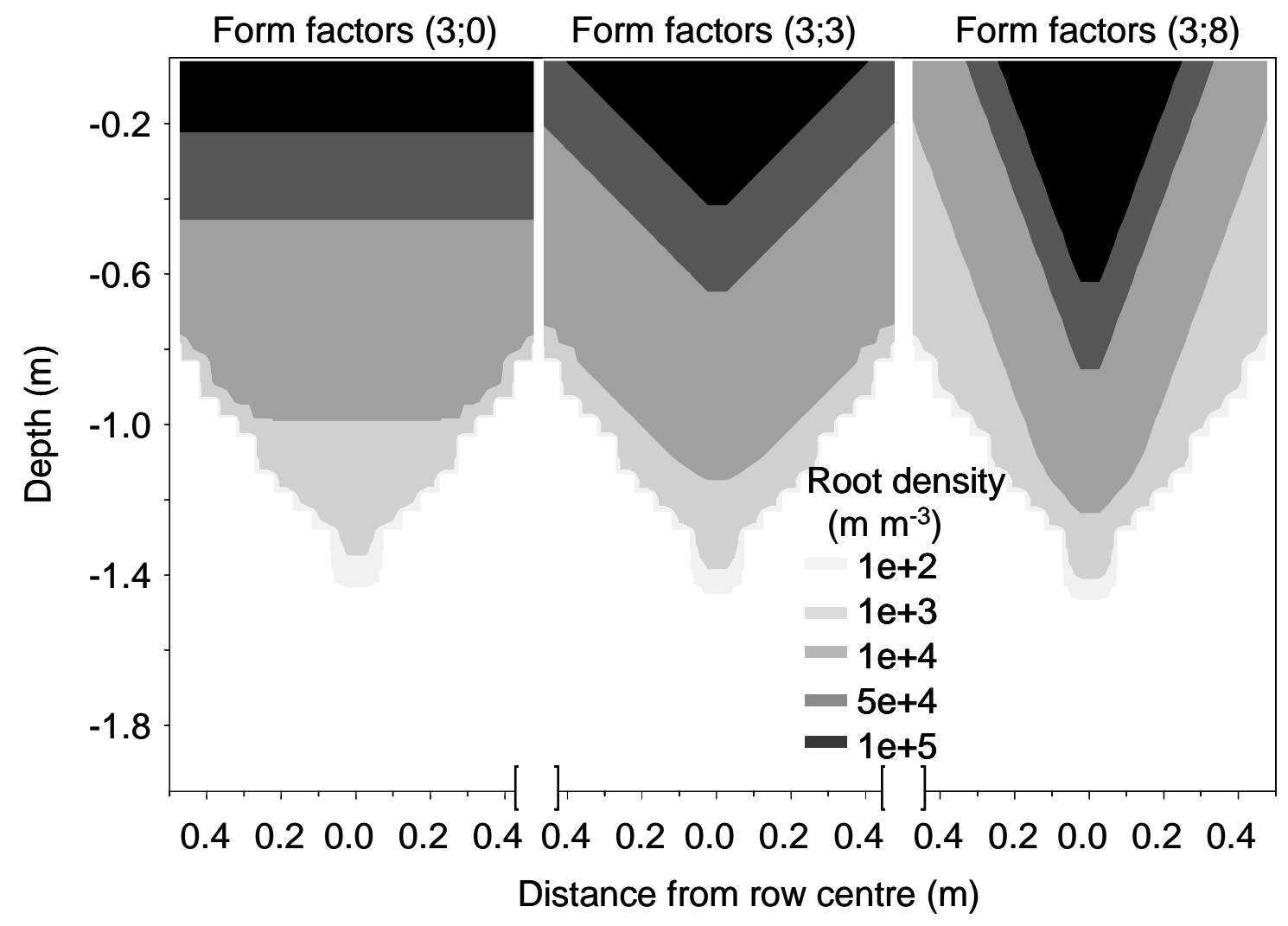

Figure 5. Root density in the soil profile in a 2-D system. Three different form parameter settings were used in 2-D:

$3\left(a_{z} ; a_{x}\right),(3 ; 0),(3 ; 3),(3 ; 8)$. Decreasing root density is indicated by decreasing intensity of shading. 


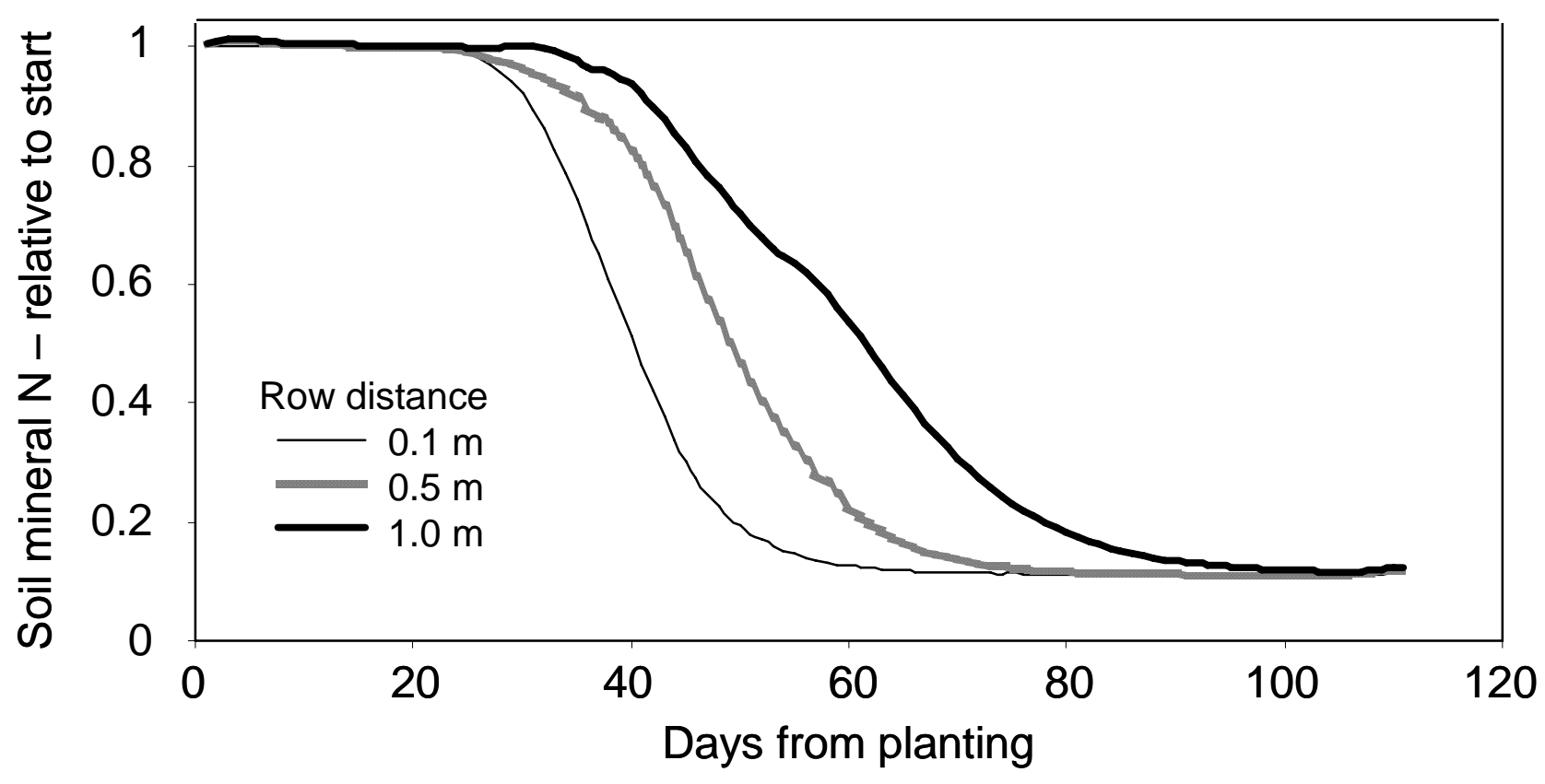

2 Figure 6. Soil mineral $\mathrm{N}$ content relative to initial value for the default root model simulated in a system with low

3 mineral $\mathrm{N}$ content. Relative soil mineral $\mathrm{N}$ content in $0.25-0.50 \mathrm{~m}$ soil layer with three different row widths, $0.1,0.5$,

4 and $1.0 \mathrm{~m}$. The $0.1 \mathrm{~m}$ row distance is simulated as 1-D. Form parameter values were $a_{z}=3$ and $a_{x}=3$. 


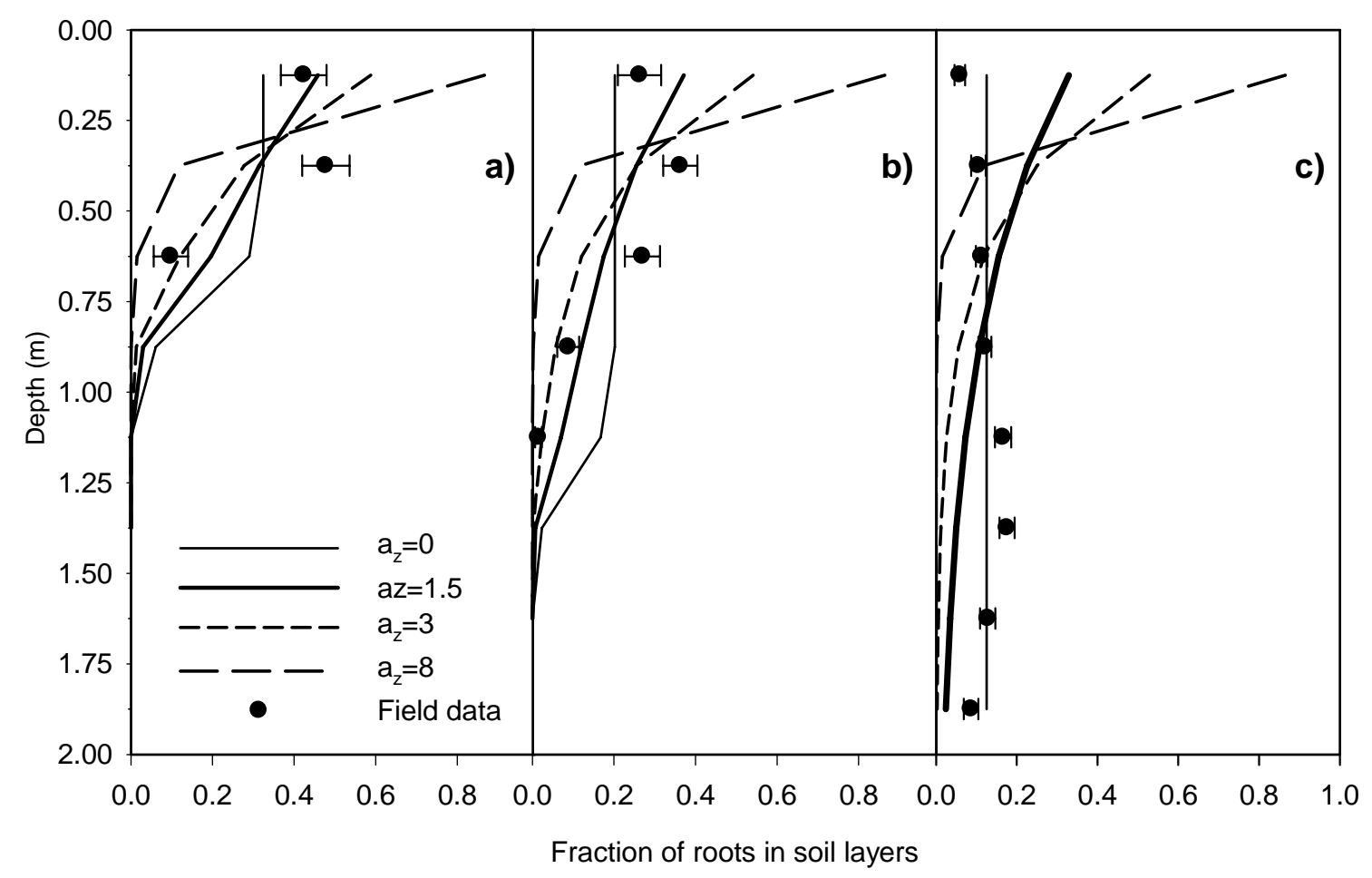

Fraction of roots in soil layers

2 Figure 7. Comparison of measured and simulated root density distribution of a white cabbage crop. The simulated data

3 were obtained using $a_{z}$ values ranging from 0 to 8 . Field root data are the average from 10 different $\mathrm{N}$ fertility

4 treatments obtained by variable $\mathrm{N}$ rates for white cabbage and a cauliflower pre-crop, and measured a) 46, b) 64, and c)

5153 days after planting of white cabbage. Values are shown relative to the total root count at harvest, and error bars

6 show $\mathrm{SE}(\mathrm{n}=10)$. 


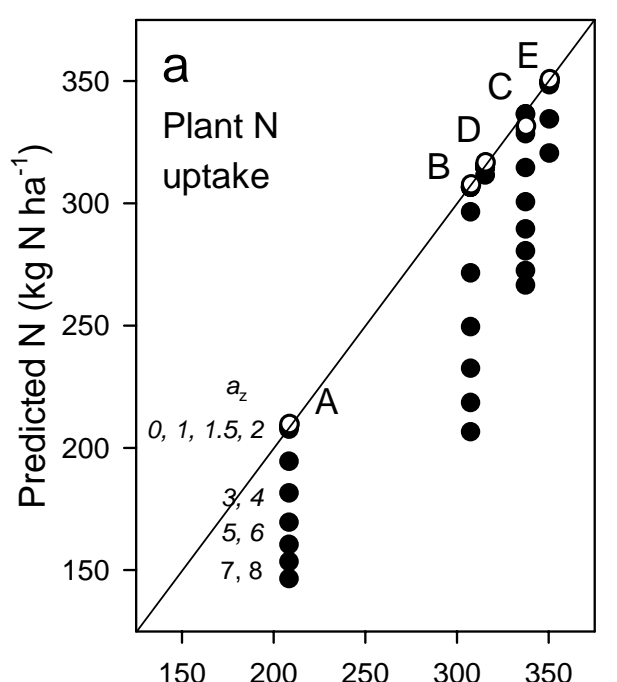

$\frac{1}{2}$

3 Figure 8. Comparisons of measured and model simulated $\mathrm{N}$ results from white cabbage grown at five $\mathrm{N}$ fertilizer

4 levels, and using different values of the form parameter $a_{z}$. a) Plant $\mathrm{N}$ uptake, b) soil mineral $\mathrm{N}$ in the 0-1.0m soil layer,

5 and c) soil mineral $\mathrm{N}$ in the 1.0-2.0 $\mathrm{m}$ soil layer. Data for each of the five fertiliser levels is shown (A to E, for fertiliser

6 levels see Materials and Methods). All fertilizer levels were simulated using $a_{z}=0$ to 8 (Open symbols show $a_{z}=1.5$,

$7 \quad$ filled symbols show $a_{z}=0,1,2,3,4,5,6,7$ and 8 .
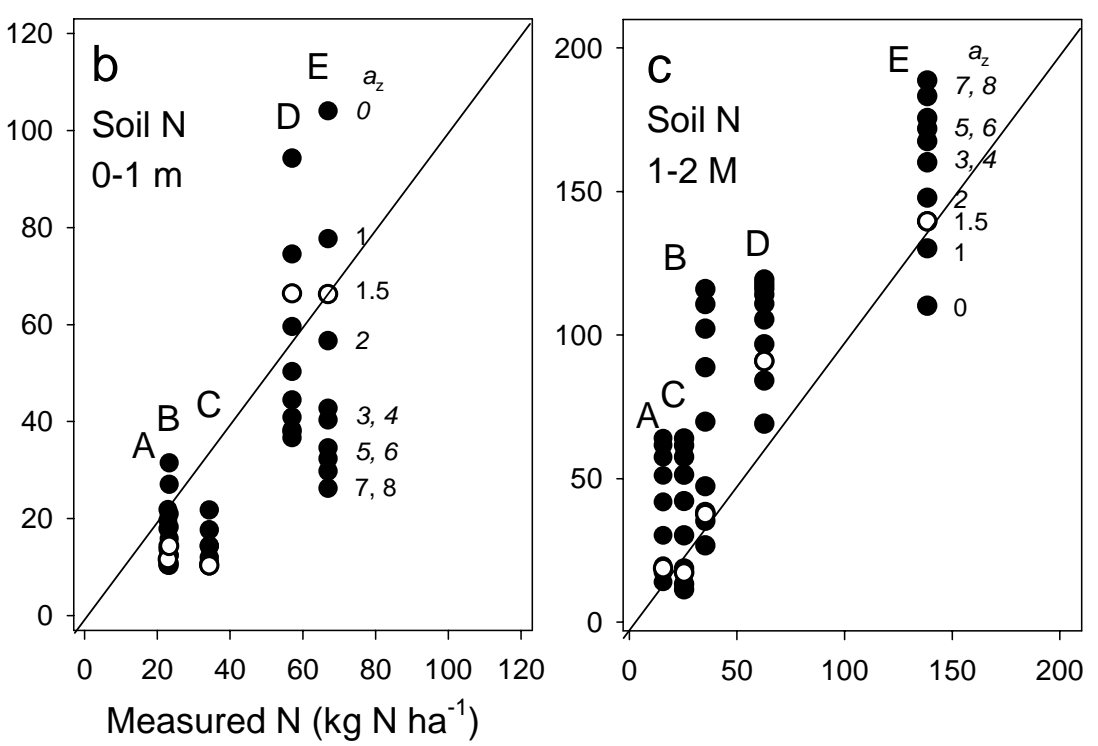


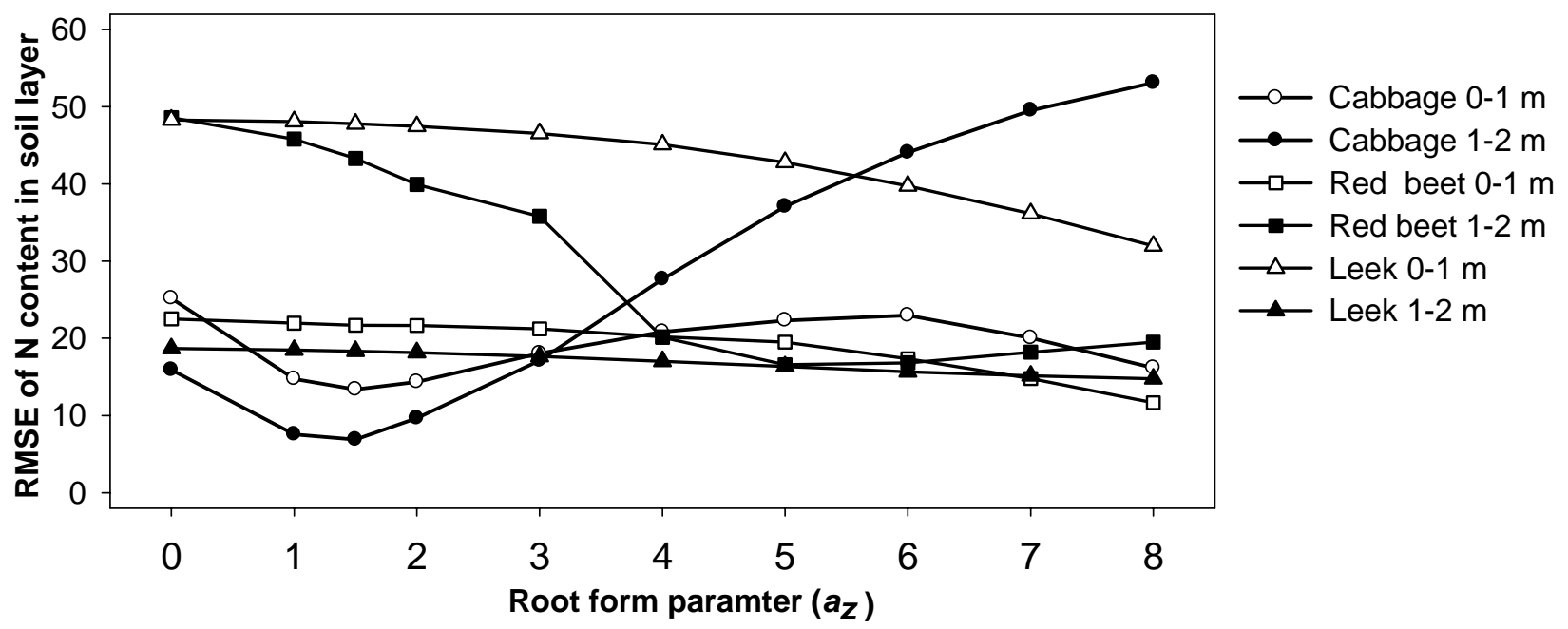

3 Figure 9. RMSE of model predicted soil mineral $\mathrm{N}$ contents in the $0.0-1.0$ and 1.0-2.0 $\mathrm{m}$ soil layers vs. measured

4 results from experiments where variation in depth distribution of soil $\mathrm{N}$ had been created by pre-crops or cover crops

5 grown in the previous year (see Figures 8b and 8c, and Thorup-Kristensen, 2006b). 


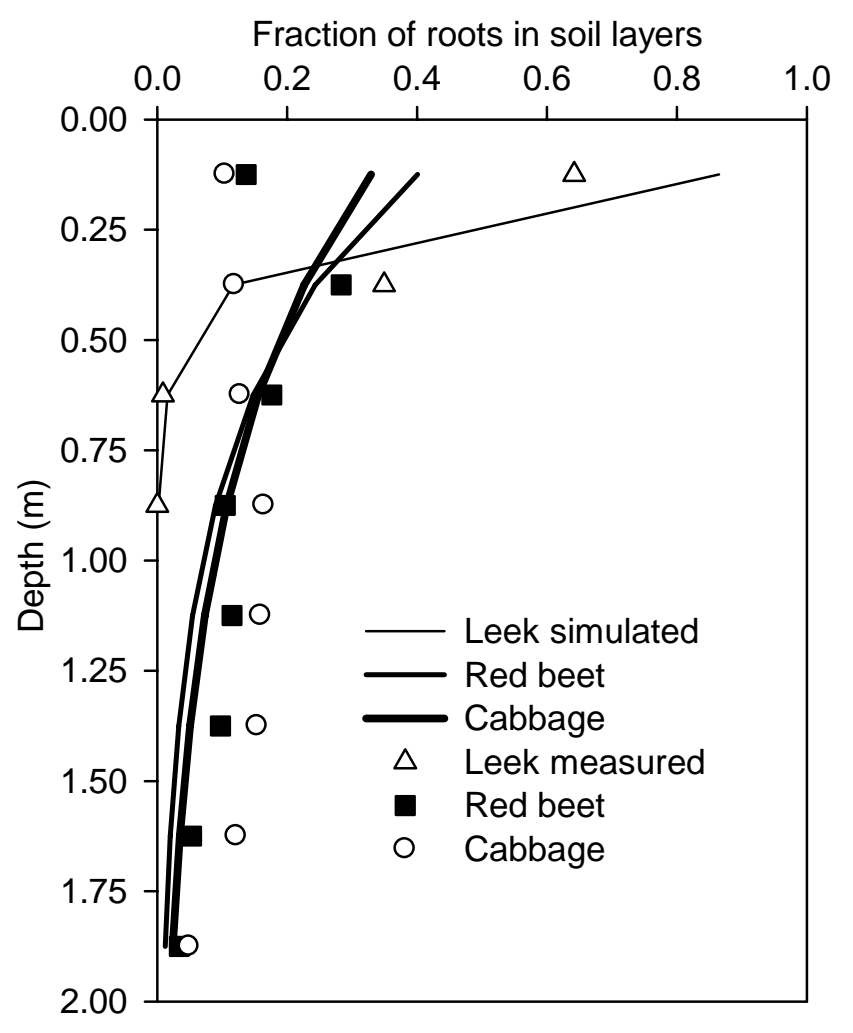

3 Figure 10. Comparison of simulated (lines) and measured root intensity (symbols) for three vegetable crops. Root

4 intensities in the field were measured on 5 September 2001 and 9 September 2002 as root intersections on grids in

5 minirhizotrons. Field data are an average of 2 years and 2 replicates. All data are shown as fraction of total root density

6 in all soil layers. Form parameter for leek was $a_{z}=8$, Red beet $a_{z}=2$ and white cabbage $a_{z}=1.5$. 

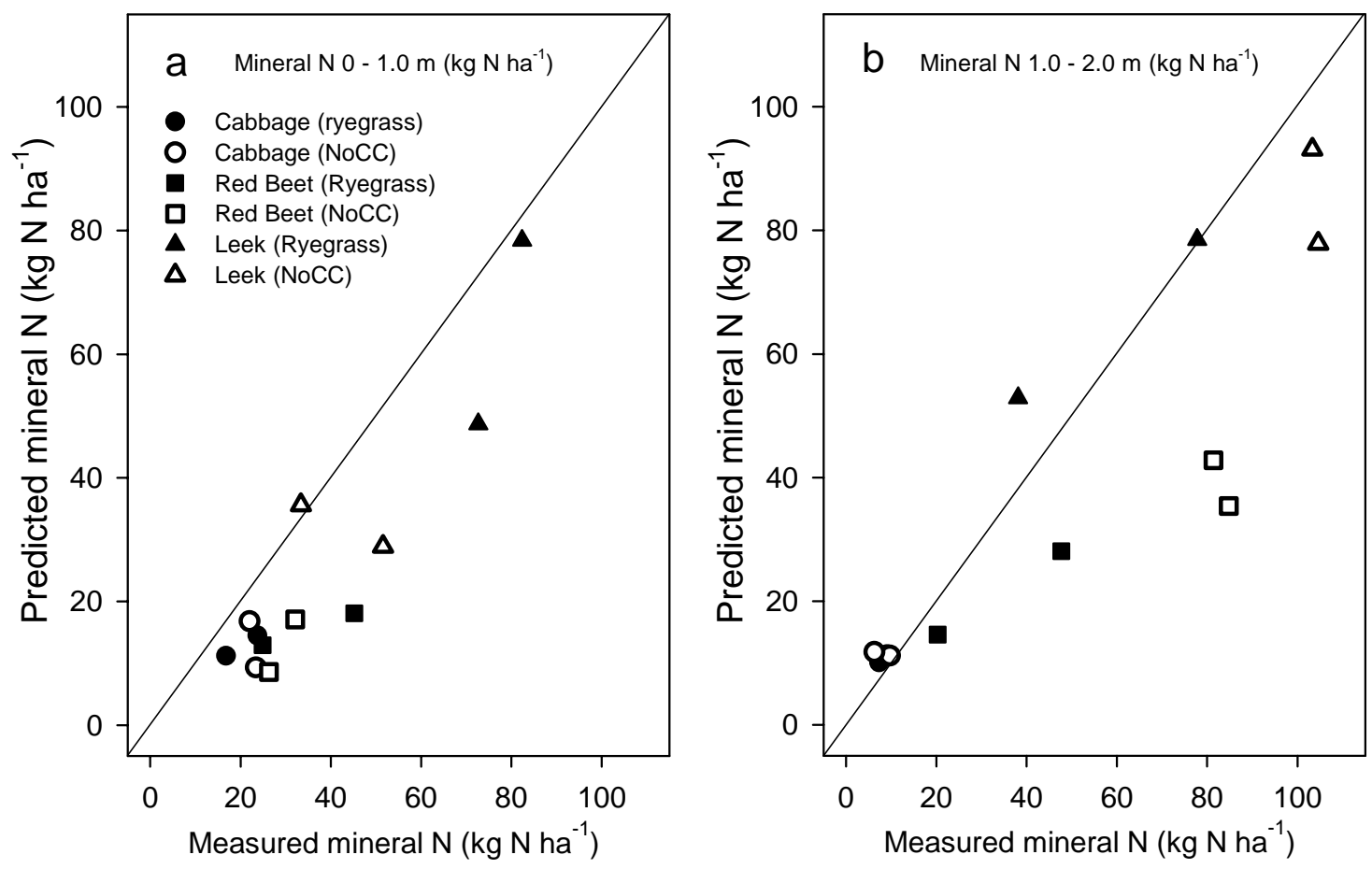

3 Figure 11. Comparison of measured and predicted data on mineral $\mathrm{N}$ in the a) $0.0-1.0 \mathrm{~m}$ and b) $1.0-2.0 \mathrm{~m}$ soil layer.

4 Simulations of three vegetable crops with ryegrass catch crop (filled symbols) or no catch crop (open symbols) in the

5 preceding year. The experiment was repeated in two years, shown here with identical symbols. Key to symbols within

6 diagram. 


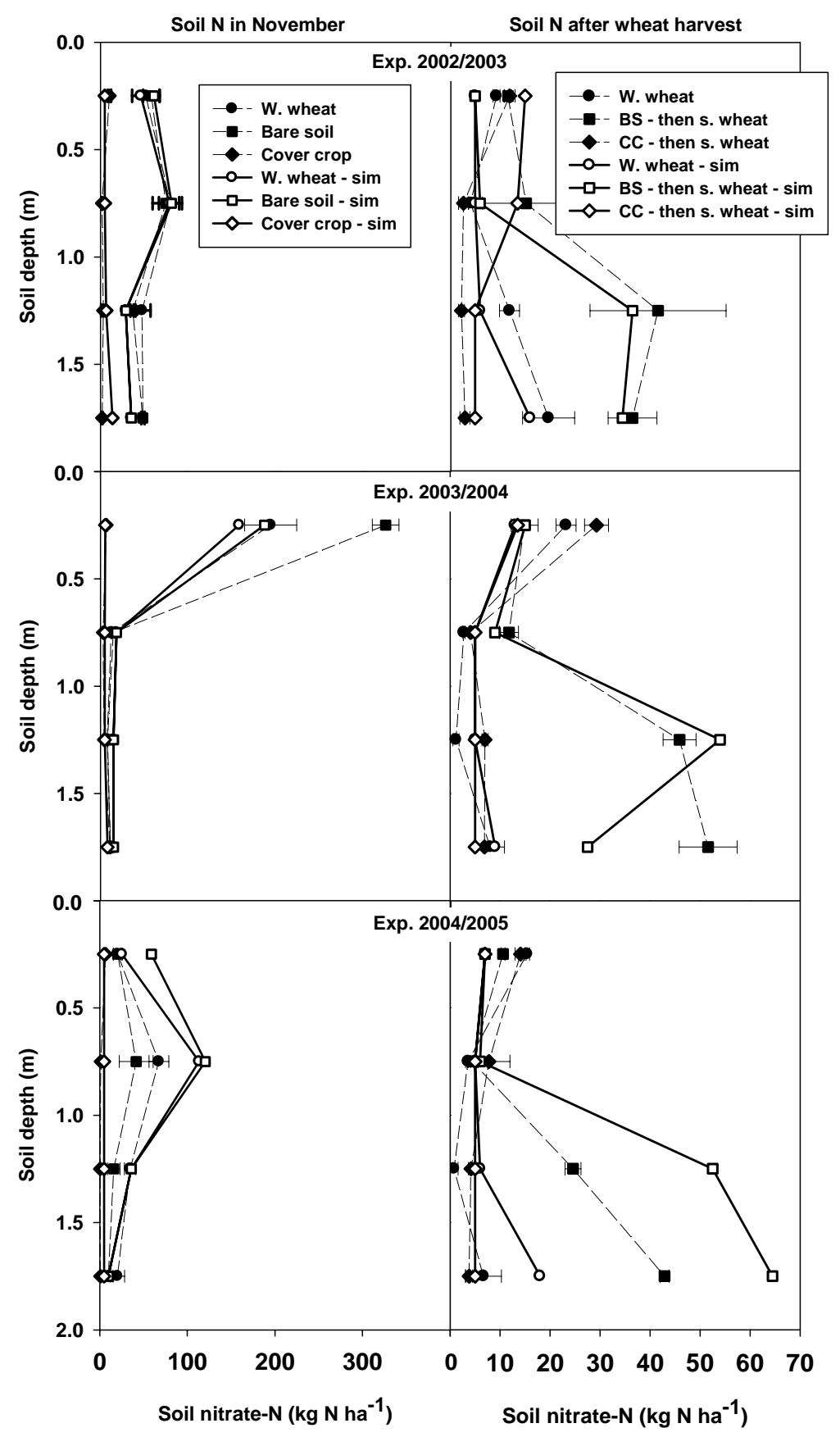

2 Figure 12. Validation of model simulation of soil inorganic $N$ content against 3 years of data from an experiment with

3 winter wheat, spring wheat and cover crops (Thorup-Kristensen et al., 2009). Left hand plots show data from November

4 under recently sown winter wheat, and in bare soil (BS) and cover crop (CC) plots where spring wheat are to be sown in

5 the spring. Right hand plots show data from August in the next year after wheat harvest. Closed symbols show

6 measured data, open symbols and dashed lines show model simulated data. Error bars show SE of measured data ( $\mathrm{n}=3$ ). 